\title{
Spacecraft Charging in Low Temperature Environments
}

\author{
Joseph I. Minow* \\ NASA Marshall Space Flight Center, Huntsville, AL 35812 USA \\ Linda N. Parker ${ }^{\dagger}$ \\ Jacobs Engineering, Marshall Space Flight Center Group, Huntsville, AL 35812 USA
}

\begin{abstract}
Spacecraft charging in plasma and radiation environments is a temperature dependent phenomenon due to the reduction of electrical conductivity in dielectric materials at low temperatures. Charging time constants are proportional to 1/conductivity may become very large (on the order of days to years) at low temperatures and accumulation of charge densities in insulators in charging environments traditionally considered benign at ambient temperatures may be sufficient to produce charge densities and electric fields of concern in insulators at low temperatures. Low temperature charging is of interest because a number of spacecraft-primarily infrared astronomy and microwave cosmology observatories-are currently being design, built, and or operated at very cold temperatures on the order of $40 \mathrm{~K}$ to $100 \mathrm{~K}$. This paper reviews the temperature dependence of spacecraft charging processes and material parameters important to charging as a function of temperature with an emphasis on low temperatures regimes.
\end{abstract}

\section{Introduction}

Q pace systems designed for operating at cryogenic temperatures are encountered in a variety of astronomical and astrophysical applications due to the low noise and better energy resolution of many photon detector systems at low temperatures and the reduced operating background at infrared (or longer) wavelengths [c.f., Collaudin and Rando, 2000]. An attractive technique to achieve low operating temperatures for long duration infrared and microwave astronomy missions is passive cooling of instrument systems by radiating excess heat to the cold $\sim 4 \mathrm{~K}$ background of space because it eliminates the risk in relying on active cooling systems which represent a potential single point failure for the mission, limited duration missions provided by on-orbit inventories of expendable cryogenic refrigerants, and reduces the spacecraft power requirements. Passive cooling designs incorporate shields to protect infrared optical components and instrument packages from the heat of the Sun [Woolf and Angel, 2000; Johnston et al., 2003]. Spacecraft configurations which allow long wavelength photons to escape to space efficiently cool the exposed surfaces to the required operating temperatures but also allow access of energetic charged particles responsible for spacecraft charging to the exposed cold sectors of the spacecraft. Spacecraft charging represents a potential threat to passively cooled systems because the buildup of excess charge on insulating materials is exacerbated by low temperatures.

Examples of spacecraft designed for low temperature operations at L2 include the Wilkerson Microwave Anisotropy Probe, the James Webb Space Telescope (JWST), and Single Aperture Far-Infrared (SAFIR) Observatory. The WMAP microwave observatory, currently in operation in orbit about L2, is designed for passive cooling to $\sim 90 \mathrm{~K}$ with $5 \mathrm{~m}$ diameter solar arrays blocking solar radiation from the instrument payload and passive radiators on the cold side of the observatory [Bennett et al., 2003]. Instruments are protected from sunlight by the solar arrays $5 \mathrm{~m}$ in diameter which form a sunshield when deployed. JWST is an infrared observatory currently under construction designed to operate at temperatures $\angle 50 \mathrm{~K}$ on the cold side of the observatory utilizing passive cooling by a $19.5 \mathrm{~m} \mathrm{x} 11.4 \mathrm{~m}$ sunshade [Gardner et al., 2006]. More ambitious yet is the proposed SAFIR spacecraft which is being designed to passively cool the payload to temperatures below the $\sim 30 \mathrm{~K}$ to $60 \mathrm{~K}$ using a large sunshade similar to the JWST design then further reduce detector temperatures to $\sim 5 \mathrm{~K}$ using active cooling systems [Lester et al., 2004].

\footnotetext{
"AST, Flight Vehicle Space Environments, Spacecraft and Vehicle Systems Department, NASA/MSFC/EV13, Huntsville, AL, Senior Member.

${ }^{\dagger}$ Environments Group Supervisor, Jacobs Engineering, MSFC Group, MSFC/EV13, Huntsville, AL.
} 
Future exploration of lunar environments will also expose materials and space systems to low temperature environments. Lunar surface temperatures during the two-week lunar night drop to values on the order of $\sim 100 \mathrm{~K}$ with localized regions cooling to $\sim 80 \mathrm{~K}$ to $\sim 90 \mathrm{~K}$ just before sunrise [Low, 1965; Mendell and Low, 1974; Vaniman et al., 1991]. More challenging yet are the permanently dark craters at the lunar poles where temperatures reach $\sim 50 \mathrm{~K}$ [Ingersoll et al., 1992; Vasavada et al., 1999; Bussey et al., 2003]. In the latter case, systems designed to operate and explore within the confines of the dark craters will have to be designed to withstand localized charge build-up in insulating materials for extended periods while the hardware is immersed in the cold, dark environments of the crater floor.

Exposure of strongly insulating materials to space plasma and radiation environments at low temperatures creates a risk of damage both to materials and to spacecraft systems due to electrostatic discharge from localized charge build-up and high electric fields. It is well known that one of the mitigation strategies recommended for avoiding detrimental effects due to spacecraft charging induced electrostatic discharges is assuring that materials have adequate conductivity to bleed off excess charge [Purvis et al., 1984; NASA, 1998]. This paper reviews the temperature dependence of spacecraft charging properties Section II, surveys their values at low temperatures in Sections III through VI, and summarizes the results in Section VII.

\section{Temperature Dependence of Spacecraft Charging Processes and Parameters}

Bulk (or deep dielectric) charging is the accumulation of charges in insulating materials or isolated conductors due when exposed to currents of energetic, penetrating charged particle currents. Relativistic electrons with energies exceeding a few tenths $\mathrm{MeV}$ are generally implicated in bulk charging anomalies in the space environment due to their greater range in shielding materials compared to ions with equivalent energies and ions with sufficient energy) tens of $\mathrm{MeV}$ ) to penetrate the same shielding thickness as the $\sim \mathrm{MeV}$ electrons typically have much smaller flux. Bulk charging is a rate problem in which a charge density accumulates in an insulating material (or isolated conductor) if the incident current charging the material exceeds the rate at which the charge can be removed through conduction. In the case of insulating materials, it is the bulk conductivity that is responsible for controlling the loss rate of charge deposited in the material. Isolated conductors will accumulate charge unless they are grounded through a resistance and the properties of the resistive material controls the charging process.

Bulk charging is typically modeled using the set of equations [Frederickson, 1980; Sessler et al., 2004]

$$
\begin{aligned}
& \nabla \cdot \mathbf{D}=\rho \\
& D=\varepsilon E \\
& \frac{\partial \rho}{\partial t}=-\nabla \bullet J
\end{aligned}
$$

where $\rho$ is the charge density, $\mathrm{D}$ and $\mathrm{E}$ the displacement and electric fields, $\mathrm{J}$ the current density, and the dielectric permittivity is related to the permittivity in free space $\varepsilon_{0}$ through the relationship $\varepsilon=\kappa \varepsilon_{0}$. where the dielectric constant $\kappa$ is defined as the ratio of the dielectric permittivity to the permittivity of free space $\kappa=\varepsilon_{/} \varepsilon_{0}$. The current density $J$ includes both the currents $\mathrm{J}_{0}$ due to the incident radiation flux as well as the conduction currents $\mathrm{J}_{\mathrm{C}}$

$$
J=J_{0}+J_{C}
$$

The conduction current is related to the electric field

$$
\begin{aligned}
J & =\sigma E \\
& =\left(\sigma_{\text {dark }}+\sigma_{\text {radiation }}\right) E
\end{aligned}
$$

where $\sigma$ is the bulk conductivity of the material which is often divided into two terms, the $\sigma_{\text {dark }}$ conductivity in the absence of exposure to photons or charged particles and $\sigma_{\text {radiation, }}$ which is an additional conductivity generated ionizing radiation. The "radiation" subscript here refers to radiation induced conductivity (RIC) which is a transient increase in conductivity produced by interaction of the radiation field with a material. RIC is a function of the radiation dose rate and should not be confused with the radiation induced electrical degradation (RIED) which is the permanent increase in the dark conductivity of ceramic insulators exposed to radiation at high temperatures and electric fields 
[Hodgson, 1992, 1998; Hodgson and Moroño, 2000]. In addition, RIED is not likely to be a significant process in low temperature environments based on reports of minimum temperature thresholds on the order of $\sim 400 \mathrm{~K}$ for the development of RIED effects [Moroño and Hodgson, 1994]. RIC is typically modeled as a dose rate dependent process

$$
\sigma_{\text {radiation }}=k\left(\frac{d \gamma}{d t}\right)^{\alpha}
$$

Where $\mathrm{k}$ is a constant of the material, $\gamma$ the dose rate, and $\alpha$ a parameter in the range $0.5<\alpha<1.0$ that depends on the distribution of trapping states that control the number of electrons that can be promoted into the conduction band [Fowler, 1956; Campbell, 1983]. The parameters $\mathrm{k}$ and $\alpha$ have been shown to be temperature dependent [Klaffky et al., 1980; Pells, 1988 ] with temperature dependent variations in $\alpha$ most prominent for $\alpha \sim 0.5$ but independent of temperature for $\alpha \sim 1.0$ [c.f., Campbell, 1983].

Spacecraft surface charging is the result of current balance on spacecraft surfaces due to collection of currents in a plasma or radiation environment. Formally, surface charging due to particles with insufficient energy the penetrate into materials is governed by the current balance equation

$$
\frac{d Q}{d t}=C \frac{d V}{d t}=\mathrm{I}_{\mathrm{net}}(\mathrm{V})
$$

where the net current to the spacecraft surface $I_{\text {net }}(V)$ includes a number of terms depending on the environment, spacecraft materials, and design [Hastings and Garrett, 1996; Garrett and Whittlesey, 2000]

$$
\frac{d Q}{d t}=C \frac{d V}{d t}=\mathrm{I}_{\mathrm{T}}(\mathrm{V})=-\mathrm{I}_{\mathrm{E}}(\mathrm{V})+\mathrm{I}_{\mathrm{I}}(\mathrm{V})+\mathrm{I}_{\mathrm{SE}}(\mathrm{V})+\mathrm{I}_{\mathrm{SI}}(\mathrm{V})+\mathrm{I}_{\mathrm{BSE}}(\mathrm{V})+\mathrm{I}_{\mathrm{PH}}(\mathrm{V})+\mathrm{I}_{\mathrm{C}} \pm \mathrm{I}_{\mathrm{a}}(\mathrm{V})
$$

where $Q$ is the charge on a body with capacitance $C$ as a function of time $t$ and the parameters are:

$\begin{array}{ll}V & \text { surface potential relative to space } \\ \mathrm{I}_{\mathrm{T}} & \text { total current to spacecraft surface at } \mathrm{V} \\ \mathrm{I}_{\mathrm{E}} & \text { incident electron current } \\ \mathrm{I}_{\mathrm{I}} & \text { incident ion current } \\ \mathrm{I}_{\mathrm{SE}} & \text { secondary emitted electron current due to } \mathrm{I}_{\mathrm{E}} \\ \mathrm{I}_{\mathrm{SI}} & \text { secondary emitted electron current due to } \mathrm{I}_{\mathrm{I}} \\ \mathrm{I}_{\mathrm{BSE}} & \text { back scattered electron current due to } \mathrm{I}_{\mathrm{E}} \\ \mathrm{I}_{\mathrm{PH}} & \text { photoelectron current } \\ \mathrm{I}_{\mathrm{C}} & \text { conduction current } \\ \mathrm{I}_{\mathrm{a}} & \text { currents from active sources including charged particle beams, } \\ & \text { thrusters, and plasma contactors }\end{array}$

Solutions to equation (2) are typically implemented on three dimensional finite element models and the network of current balance equation solved for each element. For our purposes of examining temperature dependence of surface charging, it is useful to recast equation (2) into a simpler form

$$
\frac{d V}{d t}=\frac{1}{C}\left[I_{\text {environment }}+I_{\text {sec ondary }}+\sigma V\right]
$$

where $I_{\text {environment }}$ includes the primary ion and electron currents incident on the spacecraft surface, $I_{\text {secondary }}$ is the photoelectron current and currents produced secondary electrons produced by the interaction of the primary currents with the spacecraft surface, and $\sigma \mathrm{V}$ the conduction current either through a dielectric to ground or from one element to an adjacent element.

Temperature dependent material properties controlling bulk charging in equations (1) through (6) are the dark conductivity, permittivity (or dielectric constant), and RIC parameters $\mathrm{k}$ and $\alpha$ of the material that is being charged. Parameters in the surface charging equations (7) through (9) that depend on temperature are the conductivity (including the dark component of the bulk conductivity and surface conductivity of insulating materials) and capacitance which depends on temperature through the dielectric constant of materials composing the individual capacitive elements of the spacecraft structure. In addition, surface charging can depend on the RIC component of a material which controls leakage currents through surface insulators to the underlying conducting structure. 


\section{Conductivity (Resistivity)}

The ionic electrical conductivity (= 1/resistivity) of an insulating material is given by [c.f., Seeger, 1997; Bube, $1988 ;$ Kao, 2004]

$$
\sigma(T)=\sum_{i} q_{i} n_{i} \mu_{i}
$$

where $n_{i}$ is the density of charge carriers, $q_{i}$ the charge on each carrier, and $\mu_{I}$ the mobility of the charge carrier. The conductivity is a sum because there may be several species of charge carriers present in a material which contribute to the final conductivity. Both the mobility and density of charge carriers decrease with temperature so the conductivity of insulating materials decrease with temperature.

Dielectric conductivity is modeled using a range of techniques. An Arrhenius temperature dependence is generally assumed for polymers [Wintle, 1983]

$$
\sigma(T)=\frac{A}{k T} \exp \left(-E_{A} / k T\right)
$$

where $E_{\mathrm{A}}$ is the activation energy of the material, $\mathrm{k}$ is Boltzmann's constant, and A constant of the material typically determined from the conductivity at room temperature [Rodgers et al., 2000]. Conduction at very low temperatures is the result of hopping mechanism due to the charge carriers tunneling through the potential barriers (a quantum mechanical process) between one trapping site and the next because the charge carriers may have insufficient energy to move over potential barriers. In this regime the temperature dependent conductivity is described by Mott's variablerange hopping model [Mott and Davis, 1979; Raju, 2003]

$$
\sigma(T)=A_{H} \exp \left[-\left(T_{0} / T\right)^{n}\right]
$$

where $A_{H}$ and $T_{0}$ are constants and the exponent $n$ lies in the range $0.25 \leq n \leq 0.50$. A general form for the electrical conductivity including the effect of electric fields is [Adamec and Calderwood, 1975]

$$
\sigma(E, T)=\frac{A}{k T} \exp \left(-E_{A} / k T\right)\left[\frac{2+\cosh \left(\beta_{F} E^{1 / 2} / 2 k T\right)}{3}\right]\left[\frac{2 k T}{e E \delta} \sinh \left(\frac{e E \delta}{2 k T}\right)\right]
$$

where $\mathrm{e}$ and $\mathrm{k}$ are the electron charge and Boltzmann's constant, respectively, $\delta$ an experimentally obtained hopping distance on the order of 10 's $\AA$ [Rodgers et al., 2000], and the parameter $\beta_{\mathrm{F}}=\left[\mathrm{e}^{3} / \pi \varepsilon\right]^{1 / 2}$ depends on the permittivity $\varepsilon$.

Electrical conductivity values obtained from the scientific literature, materials data books, and manufacturer's specification sheets show that conductivity decreases on the order two to four orders of magnitude can be expected when materials are cooled to very low temperatures. Some examples of bulk $\sigma_{B}\left(T_{\text {low }}\right) / \sigma_{B}\left(T_{\text {high }}\right)$ and surface $\sigma_{S}$ $\left(\mathrm{T}_{\text {low }}\right) / \sigma_{\mathrm{S}}\left(\mathrm{T}_{\text {high }}\right)$ conductivity ratios for insulating materials relevant to space applications are:

- Polypyrrole (PPy) polymer composites

[Aguilar-Hernandez andPotje Kamloth, 2001]

- Medium density polyethylene (MDPE)

cross linked polyethylene (XLPE), polyvinyl chloride (PVC), and a polymer based semiconductor (PP)

[Visiwantha and Moorching, 1994]

- Apollo 16 rock [Olhoeft et al., 1973]

Apollo 15 rock [Olhoeft et al., 1974]

Other lunar rocks

*ratio suggests the low temperature values are

outside the temperature range where the conductivity

measurements were performed [c.f, Carrier et al., 2000] .

- Polyester varnish [Gerhold, 1998]

$$
\begin{aligned}
& \sigma_{\mathrm{B}}(77 \mathrm{~K}) / \sigma_{\mathrm{B}}(\sim 300 \mathrm{~K}) \sim 4 \times 10^{-5} \\
& \sigma_{\mathrm{S}}(243 \mathrm{~K}) / \sigma_{\mathrm{S}}(\sim 293 \mathrm{~K}) \sim 10^{-1} \text { to } 2 \times 10^{-2} \\
& \sigma_{\mathrm{B}}(100 \mathrm{~K}) / \sigma_{\mathrm{B}}(\sim 300 \mathrm{~K}) \sim 1 \times 10^{-2} \\
& \sigma_{\mathrm{B}}(100 \mathrm{~K}) / \sigma_{\mathrm{B}}(\sim 300 \mathrm{~K}) \sim 9 \times 10^{-3} \\
& \sigma_{\mathrm{B}}(150 \mathrm{~K}) / \sigma_{\mathrm{B}}(\sim 300 \mathrm{~K}) \sim 10^{-18 *}
\end{aligned}
$$

$$
\begin{aligned}
& \sigma_{\mathrm{B}}(100 \mathrm{~K}) / \sigma_{\mathrm{B}}(\sim 300 \mathrm{~K}) \sim 10^{-1} \\
& \sigma_{\mathrm{B}}(50 \mathrm{~K}) / \sigma_{\mathrm{B}}(\sim 300 \mathrm{~K}) \sim 4 \times 10^{-2}
\end{aligned}
$$




\section{Dielectric Constant}

Dielectric constants $\kappa$ (relating the permittivity in the dielectric medium $\varepsilon_{\mathrm{r}}$ to the permittivity of free space $\varepsilon_{0}$ by the ratio $\left.\varepsilon_{\mathrm{r}}-\kappa \varepsilon_{0}\right)$ exhibit temperature dependence. For example, amorphous barium titanate thin films ( $2.7 \mu \mathrm{m}$ thick) deposited on copper substrates for use as capacitors in integrated electronic packages exhibit dielectric constants of 60 to 70 for high temperatures near $498 \mathrm{~K}$ and dielectric constants of approximately 20 at $173 \mathrm{~K}$ [El Kamel et al., 2006]. Most of the variation in dielectric constant however over a range of temperatures from $273 \mathrm{~K}$ to $498 \mathrm{~K}$ with only small decrease in dielectric constant when the material was cooled to $173 \mathrm{~K}$. In general dielectric constants for polymers vary little (on the order of $50 \%$ to $100 \%$ ) over a wide range of temperatures from $300 \mathrm{~K}$ to below $50 \mathrm{~K}$ compared to the large changes in volume resistivity [Reed et al., 1973; Yamaoka et al., 1995]. Some examples of dielectric constant ratios $\kappa\left(\mathrm{T}_{\text {low }}\right) / \kappa\left(\mathrm{T}_{\text {high }}\right)$ or permittivity ratios (since $\left.\varepsilon=\kappa \varepsilon_{0}\right)$ for insulating materials relevant to space applications are:

- Stycast 1266 unfilled epoxy:

- Polyimide, polypropylene, and polytetraflouroethylene

- Teflon

- Kapton

- Mylar

- Glass-ceramic

- Ethylene-propylene rubber

- Polyethylene

- polyethylene, teflon, and rexolite (cross-linked polystyrene)

- $\mathrm{Al}_{2} \mathrm{O}_{3}$

- Uplilex-R, -S films

$$
\begin{aligned}
& \kappa(200 \mathrm{~K}) / \kappa(300 \mathrm{~K}) \sim 0.7 \\
& \kappa(100 \mathrm{~K}) / \kappa(300 \mathrm{~K}) \sim 0.65 \\
& \kappa(50 \mathrm{~K}) / \kappa(300 \mathrm{~K}) \sim 0.64 \\
& \kappa(100 \mathrm{~K}) / \kappa(300 \mathrm{~K}) \sim 1 \text { to } 2 \\
& \kappa(50 \mathrm{~K}) / \kappa(300 \mathrm{~K}) \sim 1 \\
& \kappa(4.2 \mathrm{~K}) / \kappa(300 \mathrm{~K}) \sim 1.2 \\
& \kappa(4.2 \mathrm{~K}) / \kappa(293 \mathrm{~K}) \sim 0.9 \text { to } 1 \\
& \kappa(4.2 \mathrm{~K}) / \kappa(300 \mathrm{~K}) \sim 0.8 \\
& \kappa(80 \mathrm{~K}) / \kappa(300 \mathrm{~K}) \sim 0.8 \\
& \kappa(4.2 \mathrm{~K}) / \kappa(300 \mathrm{~K}) \sim 0.89 \\
& \kappa(80 \mathrm{~K}) / \kappa(300 \mathrm{~K}) \sim 0.89 \\
& \kappa(4.2 \mathrm{~K}) / \kappa(300 \mathrm{~K}) \sim 1 \\
& \kappa(80 \mathrm{~K}) / \kappa(300 \mathrm{~K}) \sim 1 \\
& \kappa(50 \mathrm{~K}) / \kappa(300 \mathrm{~K}) \sim 1.1 \\
& \kappa(50 \mathrm{~K}) / \kappa(300 \mathrm{~K}) \sim 1.1 \\
& \kappa(28 \mathrm{~K}) / \kappa(84 \mathrm{~K}) \sim 1.1 \\
& \mathrm{\kappa e}) \\
& \kappa(50 \mathrm{~K}) / \kappa(300 \mathrm{~K}) \sim 0.9 \text { to } 1 \\
& \kappa(100 \mathrm{~K}) / \kappa(300 \mathrm{~K}) \sim 1 \\
& \kappa(50 \mathrm{~K}) / \kappa(300 \mathrm{~K}) \sim 1 \\
& \kappa(10 \mathrm{~K}) / \kappa(300 \mathrm{~K}) \sim 1
\end{aligned}
$$

[Barucci et al., 1999]

[Gerhold, 1998],

[Gerhold, 1988; Shugg, 1986]

[Gerhold, 1988; Dupont, 2006a]

[Gerhold, 1988; Dupont, 2006a]

[Gerhold, 1988; Shugg, 1986]

[Gerhold, 1988; Shugg, 1986]

[Mizuno et al., 1994]

[Jacob et al., 2002 ; Shugg, 1986]

[Jacob et al., 2002]

[Krupka et al., 1994]

[Yamaoka et al., 1994]

\section{Electrical Breakdown (Dielectric) Strength}

The electrical breakdown strength (or electric strength) of insulating materials ultimately determines whether or not the magnitude of charge on a spacecraft surface or buried in an insulator is an issue. The electrical breakdown strength is the electric field at which a dielectric material can no longer sustain high electric fields and begins to conduct, often producing an arc or discharge current. Onset of discharge in insulating materials begins when the free electron production rates exceeds the rate at which they are removed from the material and an exponentially growing avalanche of free electrons is produced [Nelson, 1983; Gerhold, 1998; Kao, 2004].

Solid insulating materials generally exhibit an increase in the breakdown strength as the material is cooled to lower temperatures [Krähenbühl et al., 1994] although there is some variation in the magnitude of the effect. Gerhold [1998] notes that there is generally a limited temperature effect on dielectric strength of polymers between $300 \mathrm{~K}$ and $4 \mathrm{~K}$ unless a glass transition temperature occurs. The magnitude of the increase is typically less than a factor of $10 \mathrm{x}$ or $20 \mathrm{x}$ between $300 \mathrm{~K}$ and $100 \mathrm{~K}$ for many polymers including

- Polyvinyl alcohols, polymethyl methacrylate (PMMA), polyethylene, polystyrene, low-density polyethylene (LPDE), polythene, and polyisobutylene [cf., Griemsmann, 1968; Nelson, 1983; Kosaki et al., 1998]

- Kapton and Mylar [Dupont, 2006a,b; Tuncer et al., 2006],

- Polyvinyl chloride (PVC) [Nagao et al., 1992; Kosaki et al., 1998], 
- Fiber-reinforced plastics (FRP) utilizing high strength carbon, boron, or glass fibers imbedded in epoxy, polyester or polyamide polymer binders [Kosaki et al., 1998],

- Ethylenepropylene rubber (EPR), LDPE, cross-linked polyethylele (XLPE), and PVC [Mizuno et al., 1991; Kosaki et al., 1993, 1998],

- PVC tape and cable [Husain et al., 1998],

- $\mathrm{Al}_{2} \mathrm{O}_{3}, \mathrm{AIN}$ ceramics [Keene et al, , 2002]

In some cases, alkyl halides for example, the dielectric strength increases with decreasing temperature to maximum values in the range $225 \mathrm{~K}$ to $325 \mathrm{~K}$ but then begin to decrease as the material approach cryogenic temperatures [cf., Calderwood et al., 1952; Nelson, 1983; Mizuno et al., 1992; Nagao et al., 1992; Kosaki et al., 1998].

Comparison of thin film polymer breakdown strengths at different temperatures obtained from different sources is complicated by the fact that breakdown strengths are thickness dependent and can be fit by the relationship [c.f., Agarwal and Srivastava, 1971, 1973; Kim and Shi, 2001]

$$
E_{B}=A_{E B} x^{-n}
$$

where $A_{E B}$ is the constant of proportionality, $x$ the film thickness, and $-\mathbf{n}$ a fitting parameter. Finally, it is important to note that the failure mechanism of radiated insulators is still an area of intense study and laboratory work. Rodgers et al. [2000] warn that electrostatic discharging occurs in spacecraft materials although values of dielectric strength reported in material data books are typically greater than electric fields generated by charge densities accumulating in insulators exposed to space radiation environments. Laboratory testing is critical to assure that materials to be used in space applications can withstand the electric fields when exposed to relevant space radiation environments.

\section{Secondary Electron Yield}

Secondary electron currents $I_{S E}=I_{E} \delta_{e}(E)$ and $I_{S I}=I_{1} \delta_{i}(E)$ where $\delta_{e}(E)$ and $\delta_{i}(E)$ are the energy dependent electron yields due to electron and ion impact, respectively, often strongly control or even dominate the charged particle currents responsible for the development of spacecraft potentials. The secondary emission process is generally modeled as a temperature independent radiation transport process for the incident particle flux into a material, transport of the secondary electrons back towards the surface, and emission of the secondary electrons across the surface barrier but the secondary yields depend on the properties of the first 2 to $10 \mathrm{~nm}$ of a material and are very sensitive to the state of the material surface [c.f., Katz et al., 1986; Clerc et al., 2006]. However, it should be noted that temperature dependent secondary electron yields have been reported for some materials [Pomerantz, 1946; Rothard et al., 1988]. In addition, secondary yields can be strongly dependent on the state of the material surface due to outgassing, desorption of surface constituents, and deposition of contaminants on the material surface all of which are temperature dependent processes [Davies and Dennison, 1997; Chang et al., 2000]. Photoelectron yields can similarly be temperature dependent.

\section{Discussion and Summary}

Variations in spacecraft charging processes with temperature as shown in Section II is a complicated process which depends on material properties, spacecraft configuration, and interactions with the space environment. Insulating materials are used for a variety of applications on spacecraft. Polymers are widely used because they are light, strong with excellent thermal properties for a wide variety of applications. Dielectric paints and coatings are used for thermal control on spacecraft surfaces, polymer layers are incorporated into multi-layer insulation thermal blankets. Polymers including polymer composites used for structural elements for strength and light weight. Ceramic oxides including anodized aluminum (A1203) and beta cloth (SiO2) are used for a number of applications. Polymers typically encountered for a range of space applications include polyimides (Kapton), polyethylene terepthalate (Mylar), Teflon, Kevlar (incorporated into meteor shields). Temperature dependence of these valuesparticularly at cryogenic temperatures-are often difficult to obtain from the literature and particularly under the vacuum conditions appropriate for space applications. While extrapolating electrical properties measured above the glass transition temperature $\left(\mathrm{T}_{\mathrm{g}}\right)$ to temperatures below $\mathrm{T}_{\mathrm{g}}$ is not recommended, a number of polymers used in aerospace industry exhibit $\mathrm{T}_{\mathrm{g}}$ values of $300 \mathrm{~K}$ to $500 \mathrm{~K}$ or greater [Cotts and Reyes, 1986] so electrical properties 
available from the high end of the temperature range below $T_{g}$ may be extrapolated for preliminary analyses when measurements are not available.

A convenient method to evaluate the effects of temperature is to perform charging analyses using standard methods for computing potentials and fields on spacecraft surfaces and charge densities and fields in insulators exposed to radiation currents. Charging studies to determine the behavior of a space system at low temperatures are best conducted with electrical properties measured using the actual flight materials.

Mitigation of detrimental charging effects at very low temperatures is accomplished using the standard design guidelines for spacecraft in charging environments [Purvis et al., 1984; NASA, 1998] including

- use of materials with sufficient conductivity (surface and bulk) to avoid local accumulation of high charge densities,

- grounding of all isolated conductors,

- application of shielding to reduce the incident electron flux, and

- use of filtering or other current limiting hardware to protect sensitive electronic systems from damage should electrostatic discharging occur.

Application of these design guidelines at low temperatures require that material selection include consideration of the reduced material conductivity at the system operating temperatures. For example, selection of a dielectric material for use over a conducting surface with a bulk resistivity $\sim 10^{10} \Omega$-cm may have sufficient conductivity to bleed charge at room temperature and meet the $<10^{11} \Omega$-cm resistivity requirement given in Purvis et al. [1984], but the same material may fail to serve as a conductive surface at a temperature of $50 \mathrm{~K}$ because the charge can no longer move through the insulating material.

Finally, we comment that it certainly is possible to design and operate spacecraft in cold environments where they are exposed to charging environments. WMAP, for example, was carefully designed to mitigate the effects of surface and bulk charging on the cold side of the observatory [Bennett et al., 2003; Limon et al., 2006]. Dielectric materials used on the dark side of the observatory included carbon loaded ("black") kapton and conductive indium tin oxide coatings on Teflon, silver Teflon, and paint to reduce the surface resistivity of the insulating materials. Potential bulk charging issues are mitigated by shielding all susceptible circuits with a minimum of $0.16 \mathrm{~cm}$ equivalent aluminum, wrapping exposed cables with grounded layers of copper and lead foil to reduce the flux of energetic electrons to levels insufficient to produce electrostatic discharges, and particularly sensitive systems are protected from discharge currents by filters or diode limiters. WMAP is currently operating successfully at L2 after passing multiple times through the strong charging environments of the Earth's radiation belts while executing a series of phasing loops required to achieve the necessary orbit to reach $\mathrm{L} 2$ and has been exposed to solar energetic particle events while on station at L2 [Limon et al., 2006].

\section{References}

Adamec, V., and J.H. Calderwood, J. Phys. D, 8, 551-560, 1975.

Agarwal, V.K., and V K. Srivastava, Thickness dependence of breakdown field in thin films, Thin Solid Films, Vol. 8, pp. 377-381, 1971.

Agarwal, V.K., and V. K. Srivastava, Thickness dependent studies of dielectric breakdown in Langmuir thin molecular films, Solid State Communications, Vol. 12, pp. 829-834,1973.

Aguilar-Hernández, J., and $\mathrm{K}$ Potje-Kamloth, Evaluation of the electrical conductivity of polypyrrole polymer composites, J. Phys. D: Appl. Phys., 34, 1700-1711, 2001.

Barucci, M., G. Bianchini, E. Gottardi, I. Peroni, and G. Ventura, Dielectric properties of Stycast 1266 over the 0.07-300K temperature range, Cryogenics, 39, 963 - 966, 1999.

Bennett, C.L., , M. Bay, M. Halpern, G. Hinshaw, C. Jackson, N. Jarosik, A. Kogut, M. Limon, S.S. Meyer, L. Page, D.N. Spergel, G.S. Tucker, D.T. Wilkinson, E. Wollack, E.L. Wright, The Microwave Anisotropy Probe (MAP) Mission, The Astrophys. $J$., in press, 2001.

Bube, R.H., Electrons in Solids, An Introductory Survey, Second Edition, Academic Press, Inc., 1988.

Bussey, D.B.J., P.G. Lucey, D. Steutel, M.S. Robinson, P.D. Spudis, and K.D. Edwards, Permanent shadow in simple craters near the lunar poles, Geophys. Res. Lett., VOL. 30, NO. 6, 1278, doi:10.1029/2002GL016180, 2003.

Bennett, C.L., M. Bay, M. Halpern, G. Hinshaw, C. Jackson, N. Jarosik, A. Kogut, M. Limon, S. S. Meyer, L. Page, D. N. Spergel, G. S. Tucker, D. T. Wilkinson, E. Wollack, and E. L.Wright. The Microwave Anisotropy Probe Mission. ApJ, 583:1-23, January 2003. 
Calderwood, J.H., R. Cooper, and A.A. Wallace, The electric breakdown of alkali halide crystals, Proc. Phys. Soc. $B, 65,301-302,1952$.

Campbell, F.J., Radiation effects on the electrical properties of solid insulation, in "Engineering Dielectrics Volume IIA Electrical Properties of Solid Insulating Materials: Molecular Structure and Behaviour," pp 619-662, R. Bartnikas and R.M. Eichorn, (eds)., ASTM Special Technical Publication 783, ASTM, 1983.

Carrier, III, W.D., G.R. Olhoeft, and W. Mendell, in "Lunar Source Book, a Users Guide to the Moon," pp. 465 594, G.H. Heiken, D.T. Vaniman, and B.M. French, (eds.), Cambridge University Press, 1991.

Chang, W.Y., J.R. Dennison, J. Kite, and R.E. Davies, Effects of evolving surface contamination on spacecraft charging, AIAA-2000-0868, 2000.

Clerc, S., J.R. Dennison, R. Hoffmann, and J. Abbott, On the computation of secondary electron emission models, IEEE Trans. Plasma Sci., 34, 2219-2225, 2006.

Collaudin, B., and N. Rando, Cryogenics in space: a review of the missions and of the technologies, Cryogenics, 40, $797-819,2000$.

Cotts, D.B. and Reyes, Z., Electrically Conductive Organic Polymers for Advanced Applications, William Andrew Publishing/Noyes, 1986.

Davies, R.E., and J.R. Dennison, Evoluation of secondary electron emission characteristics of spacecraft surfaces, $J$. Spacecraft, 34, $571-574,1997$.

Dupont, Summary of properties for Kapton® polyamide films, 2006a.

(available at http:/ www 2.dupont.com/Kapton/en US/assets/downloads/pdf/summaryofprop.pdf, 2006)

Dupont, Mylarß polyester film, electrical properties, $2006 \mathrm{~b}$.

(available at http:/www.dupontteijinfilms,com/datasheets/mylar/productinfo/properties/h32192-1.pdf,2006)

El Kamel, F., P. Gonon, and F. Jomni, Electrical properties of low temperature deposited amorphous barium titanate thin films as dielectrics for integrated capacitors, Thin Solid Films, 504, 210 - 204, 2006.

Fowler, J.F., X-ray induced conductivity in insulating materials, Proceedings of the Royal Society of London, 236, $464-480,1956$.

Frederickson, A.R., Radiation induced dielectric charging, in "Space Systems and their Interactons with Earth's Space Environment," H.B. Garrett and C.P. Pike, (eds.), pp. 386 - 412, Vol. 71 Progress in Astronautics and Aeronautics, American Institute of Astronautics and Aeronautics, 1980.

Garrett, H.B., and A.C. Whittlesey, Spacecraft charging, an update, IEEE Trans. Plasma Sci., 28, 2017, 2000.

Gardner et al., The James Webb Space Telescope, Space Science Reviews, in press, 2006.

Gerhold, J., Properties of cryogenic insulants, Cryogenics, 38, 1063 - 1081, 1998.

Griemsmann, J.W., Fundamental properties of electrical insulation materials, in "Plastics for Electrical Insulation," P.F. Bruins (ed), pp 1 - 35, Interscience Publishers, 1967.

Hastings, D., and H.B. Garrett, Spacecraft-Environment Interactions, Cambridge University Press, 1996.

Hodgson, E.R., Radiation enhanced electrical breakdown in fusion insulators from dc to $126 \mathrm{MHz}$, J. Nucl. Mater., Vol 191-194, Part 1, 552-554, 1992.

Hodgson, E.R., General radiation problems for insulating materials in future fusion devices, J. Nucl. Mater., 258$263,1998$.

Hodgson, E.R., and A. Moroño, An initial model for the RIED effect, J. Nucl. Mater., Vol. 283-287, Part 2, 880 $884,2000$.

Husain, E., M.M. Mohsin, and S.R.S. Naqvi, Insulating materials for super-conductors, their characteristics at cryogenic temperature, 1998 IEEE International Conference on Conduction and Breakdown in Solid Dielectrics, Västerås, Sweden, 22-25 June 1998.

Ingersoll, A. P., T. Svitek, and B. C. Murray, Stability of polar frosts in spherical bowl-shaped craters on the Moon Mercury, and Mars, Icarus, 100, 40- 47, 1992.

Jacob, M.V., J. Mazierska, K. Leong, and J. Krupka, Microwave properties of low-loss polymers at cryogenic temperatures, IEEE Transactions on Microwave Theory and Techniques, 50, 474-480, 2002.

Johnston, J., B. Ross, J. Blandino, J.Lawrence, and C. Perrygo, Development of Sunshield Structures for Large Space Telescopes, Proceed. SPIE, 4850, 209-220, in IR Space Telescopes and Instruments, J.C. Mather, ed., March, 2003.

Kao, K.C., Dielectric phenomena in solids, Elsevier Academic Press, 2004.

Katz, I., M. Mandell, G. Jongeward, and M.S. Gussenhoven, The importance of accurate secondary electron yields in modeling spacecraft charging, J. Geophys. Res., 91, 13739-13744, 1986.

Kim, H.K., and F.G. Shi, Thickness dependent dielectric strength of a low-permittivity dielectric film, IEEE Trans. Dielectrics Electrical Insulation, 8, 248 - 252, 2001. 
Keene, H., J. Dickens, A. Neuber, Surface flashover across ceramic disks in vacuum at cryogenic temperatures, Power Modulator Symposium, 2002 and 2002 High-Voltage Workshop. Conference Record of the Twenty-Fifth International, pp 293 - 296, 30 June-3 July 2002.

Klaffky, R.W., B.H. rose, A.N. Goland, G.J. Dienes, Phys. Rev. B., 21, 3610, 1980.

Kosaki, M., M. Nagao, N. Shimizu, and Y. Mizuno, Solid insulation and its deterioration, Cryogenics, 38, 1095 1104, 1998.

Kosaki, M., A. Minoda, Y. Mitsuyama, Y. Mizuno, and M. Nagao, Treeing of ethylene-propylene rubber in cryogenic temperature region, Conference on Electrical Insulation and Dielectric Phenomena, 1993. Annual Report, pp. $701-706,17-20$ October 1993.

Krähenbühl, F., B. Bernstein, M. Danikas, J. Densley, K. Kadotani, M. Kahle, M. Kosaki, H. Mitsui, M. Nagao, J. Smit, and T. Tanaka, Properties of electrical insulating materials at cryogenic temperatures: a literature review, IEEE Electrical Insulation Magazine, 10, 10 - 22, 1994.

Krupka, J., R.G. Geyer, M. Kuhn, and J.H. Hinken, Dielectric properties of single crystals of $\mathrm{Al}_{2} \mathrm{O}_{3}, \mathrm{LaAlO}_{3}$, $\mathrm{NdGaO}_{3}, \mathrm{SrTiO}_{3}, \mathrm{MgO}$ at cryogenic temperatures, IEEE Transactions on Microwave Theory and Techniques, 42, 1886 - 1890, 1994.

Lester, D., D. Benford, A. Blain, C.M. Bradford, M. Dragovan, W. Langer, C. Lawrence, D. Leisawitz, J. Mather, S.H. Moseley, L. Mundy, G. Rieke, G. Stacey, H. Yorke, E. Young, The Science Case and Mission Concept for the Single Aperture Far-Infrared (SAFIR) Observatory, Proc. SPIE, Astronomical Telescopes and Instrumentation, AS04-AS01-179., 2004.

Limon, M., et al., (editor), Wilkinson Microwave Anisotropy Probe (WMAP): Three-Year Explanatory Supplement, (Greenbelt, MD: NASA/GSFC), 2006, available in electronic form at http://lambda.gsfc.nasa.gov.

Low, F.J., Ap. J, 142, $806-808,1965$.

Mendell, W.W., and F.J. Low, Preliminary results of the Apollo 17 infrared scanning radiometer, Earth, Moon, and Planets, 9, $97-103,1974$.

Mizuno, Y., Y. Mitsuyama, M. Nagao, and M. Kosaki, Dielectric properties of ethylene-propylene rubber in cryogenic temperature region, Proc. of the $4^{\text {th }}$ International Conference on Properties and Applications of Dielectric Materials, Paper 5105, Brisbane, Australia, 3-8 July 1994.

Mizuno, Y., M. Nagao, M. Kosaki, N. Shimizu, and K. Horii, Evaluation of ethylene-propylene rubber as electrical insulating material for a superconducting cable, IEEE Trans. Electr. Insul., 27, 1108-1117, 1991.

Moroño, A., and E. R. Hodgson, A lower temperature limit for the RIED effect, Journal of Nuclear Materials, Volumes 212-215, Part 2, 1119-1122, 1994.

Mott, N.F. and E.A. Davis, Electronic Processes in Non-Crystalline Materials, Oxford, 1979.

Nagao, M., M. Kosaki, and Y. Mizuno, On temperature dependence of electric strengths of polar polymeric films in low-termperature region, IEEE, 1992.

NASA, Avoiding problems caused by spacecraft on-orbit internal charging effects, NASA-HDBK-4002, NASA, 1998.

Nelson, J.K., Breakdown Strength of Solids, in "Engineering Dielectrics Volume IIA Electrical Properties of Solid Insulating Materials: Molecular Structure and Behaviour," pp 445 - 520, R. Bartnikas and R.M. Eichorn, (eds)., ASTM Special Technical Publication 783, ASTM, 1983.

Olhoeft G. R., Frisillo A. L., Strangway D. W., and Sharpe H., Temperature dependence of electrical conductivity and lunar temperatures, The Moon, 9, 79-87, 1974.

Olhoeft G. R., Strangway D. W., and Frisillo A. L., Lunar sample electrical properties, Proc. Lunar Sci. Conf. 4th, pp. 3133-3149, 1973.

Pells, G.P., J. Nucl. Mater., 155-157 (1988) 67, 1988.

Pomerantz, M., The temperature dependence of secondary electron emission from oxide-coated cathodes, Phys. Rev., 70, 33-40, 1946.

Purvis, C.K., H.B. Garrett, A.C. Whittlesey, and N.J. Stevens, Design guidelines for assessing and controlling spacecraft charging effects, NASA TP-2361, NASA, 1984.

Raju, G.G., Dielectrics in Electric Fields, Marcel Dekker, Inc., New York, NY, 2003.

Reed, R.P., R.E. Schramm, and A.F. Clark, Mechanical, thermal, and electrical properties of selected polymers, Cryogenics, 13, 67-82, 1973.

Rodgers, D.J., KA. Ryden, G.L. Wrenn, P.M. Latham, J. Sørensen, and L. Levy, An engineering tool for the prediction of internal dielectric charging, $6^{\text {th }}$ Spacecraft Charging Technology Conference, AFRL-VS-TR$20001578,2000$. 
Rothard, H., P. Lorenzen, N. keller, O. Heil, D. Hofmann, J. Kemmler, K. Kroneberger, S. Lencinas, and K.O. Groeneveld, Temperature-dependent secondary electron yield from ion bombardment of gold and copper oxide superconductors, Phys. Rev. B., 38, 9224-9226, 1988.

Sessler, G.M., M.T. Figueiredo, and G.F. Leal Ferreira, Models of charge transport in electron-bream irradiated insulators, IEEE Transactions on Dielectrics and Electrical Insulation, 11, 192 - 202, 2004.

Seeger, K., Semiconductor Physics, An Introduction, $6^{\text {th }}$ Edition, Springer, 1997.

Shugg, W.T., Handbook of Electrical and Electronic Insulating Materials, Van Nostrand Reinhold Company, 1986.

Tuncer, E., D.R. James, I. Sauers, A.R. Ellis, and M.O. Pace, On dielectric breakdown statistics, J. Phys. D.: Appl. Phys. 39, $4257-4268,2006$.

Vaniman, D., R. Reedy, G. Heiken, G. Olhoeft, and W. Mendell, The Lunar Environment, in Lunar Sourcebook, a User's Guide to the Moon, Heiken, G.H., D.T. Vaniman, and B.M. French (editors), Cambridge University Press, 1991.

Yamaoka, H., K. Miyata, and O. Yano, Cryogenic properties of engineering plastic films, Cryogenics, 35, 787 $789,1995$.

Vasavada, A. R., D. A. Paige, and S. E. Wood, Near-Surface Temperatures on Mercury and the Moon and the Stability of Polar Ice Deposits, Icarus, 141, 179- 193, 1999.

Viswanatha, C., and S.N. Moorching, Influence of low temperature conditioning on the electrical and mechanical properties of dielectrics, Paper 5103, Proc. of the $4^{\text {th }}$ International Conference on Properties and Applications of Dielectric Materials, Brisbane, Australia, 3-8 July 1994.

Wintle, H.J., Conduction processes in polymers, in "Engineering Dielectrics Volume IIA Electrical Properties of Solid Insulating Materials: Molecular Structure and Behaviour," pp 239 - 354, R. Bartnikas and R.M. Eichorn, (eds)., ASTM Special Technical Publication 783, ASTM, 1983.

Woolf, N.J., J.R.P. Angel, Passive cooling of gossamer telescopes, Proc. SPIE, 4091, 39-42, in Imaging Technology and Telescopes, J.W. Bilbro, J.B. Breckinridge, R.A. Carreras, S.R. Czyzak, M.J., Eckart, R.D. Fiete, and P.S. Idell, eds., October, 2003. 

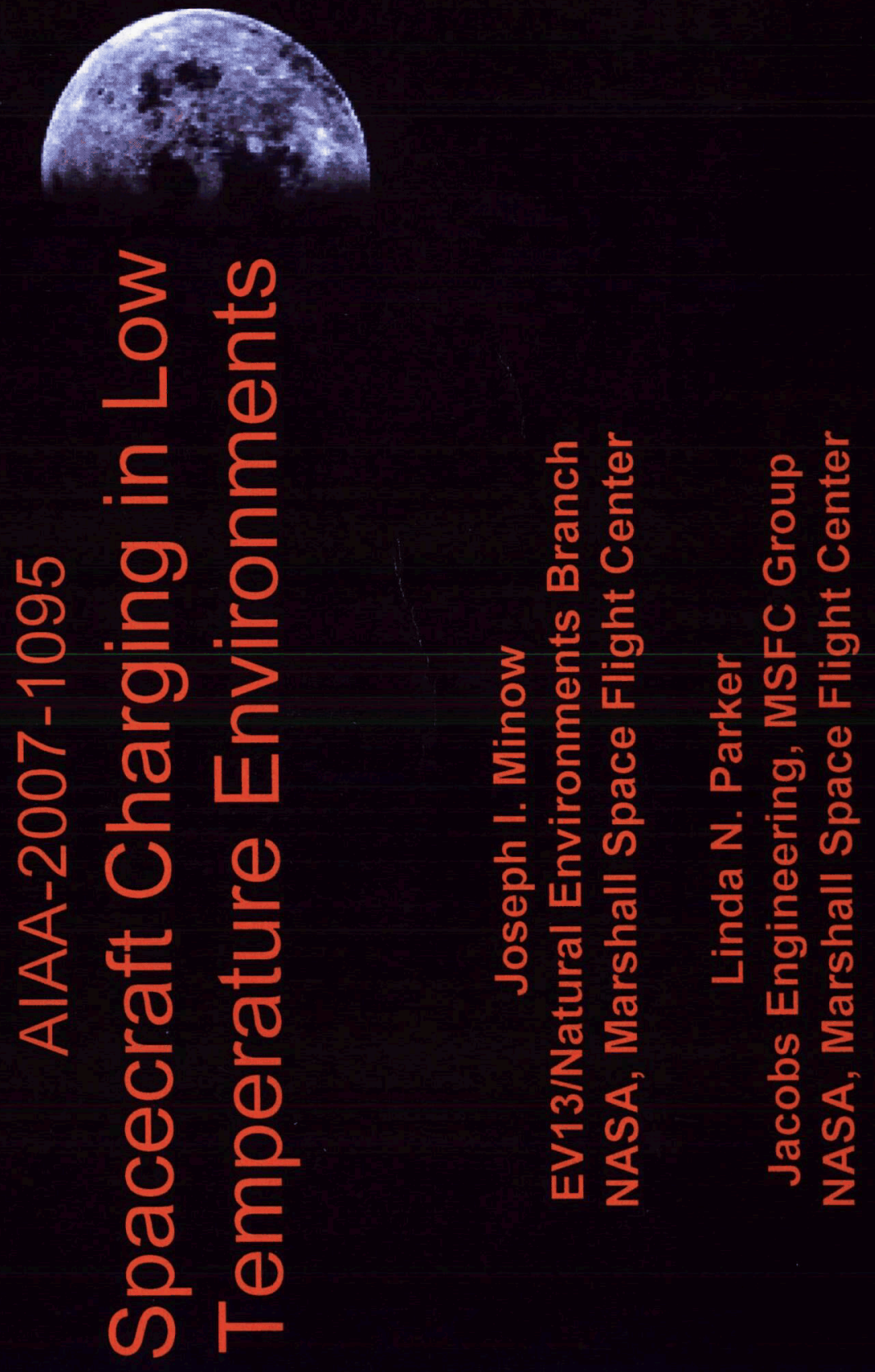

이

S

(1)

)

g

(1)

ऽ

$\frac{2}{2} \sqrt{10}$

क -

(1)

రీ

(1)

요

\%

क)

र

$\tau$

$\frac{\pi}{\pi}$ ?

$=0$ 
(1)

$\frac{0}{0}$

(1)

으

이

ชั

$\frac{3}{0}$

등

$\frac{\bar{v}}{0}$

世

$\frac{0}{0}$

(1)

$\frac{0}{\infty}$

드

$\frac{\infty}{0}$

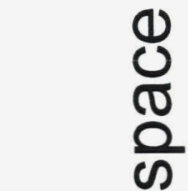

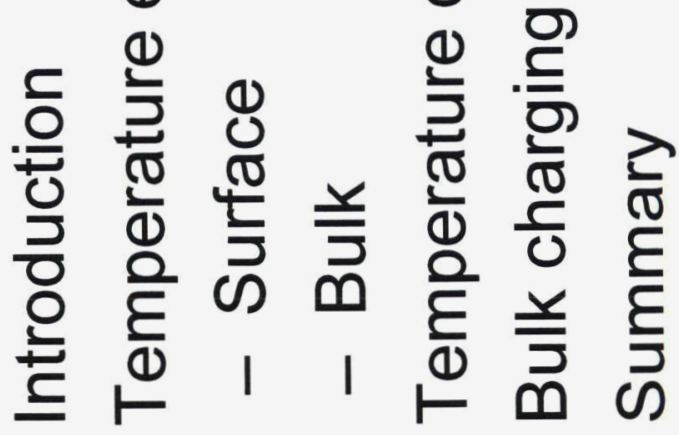




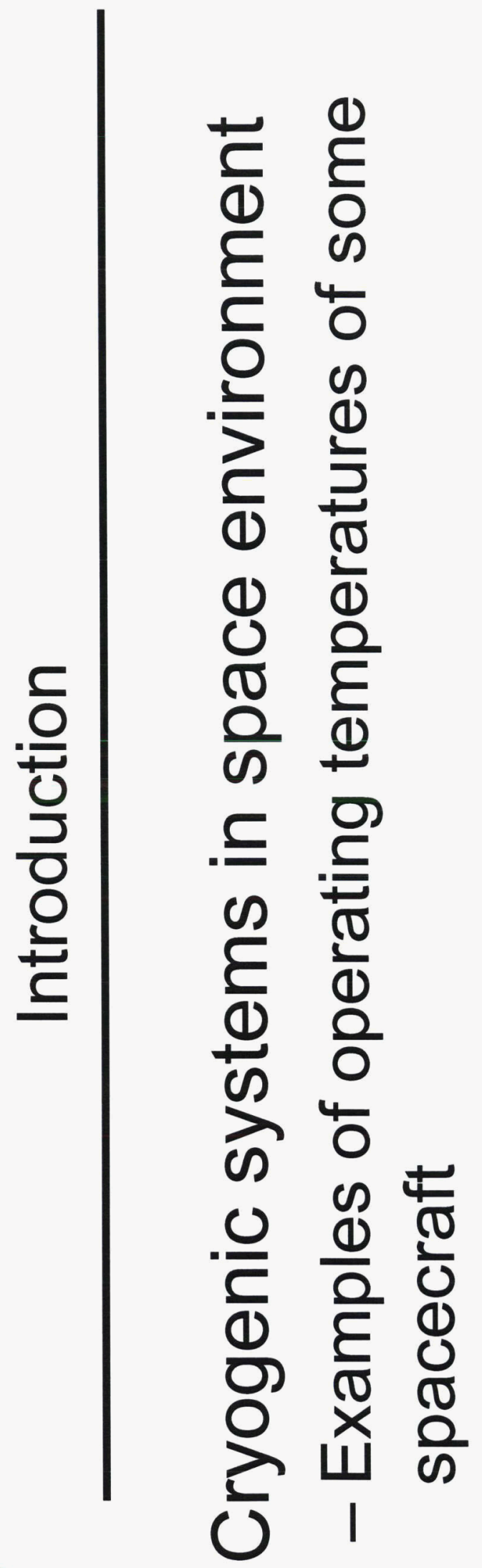




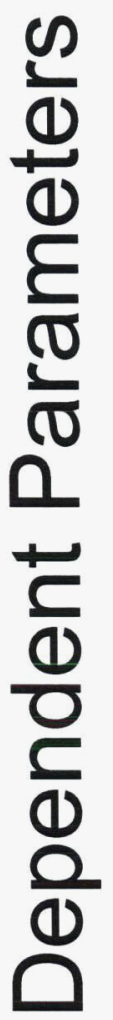

(1)

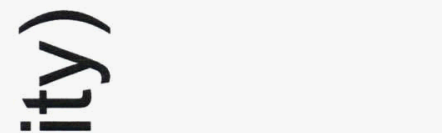

을

(1)

$\rightarrow \varepsilon$

능

이

ह

$\geqslant 0$

$\geq 8$

$0 \frac{0}{0}$

를 틀

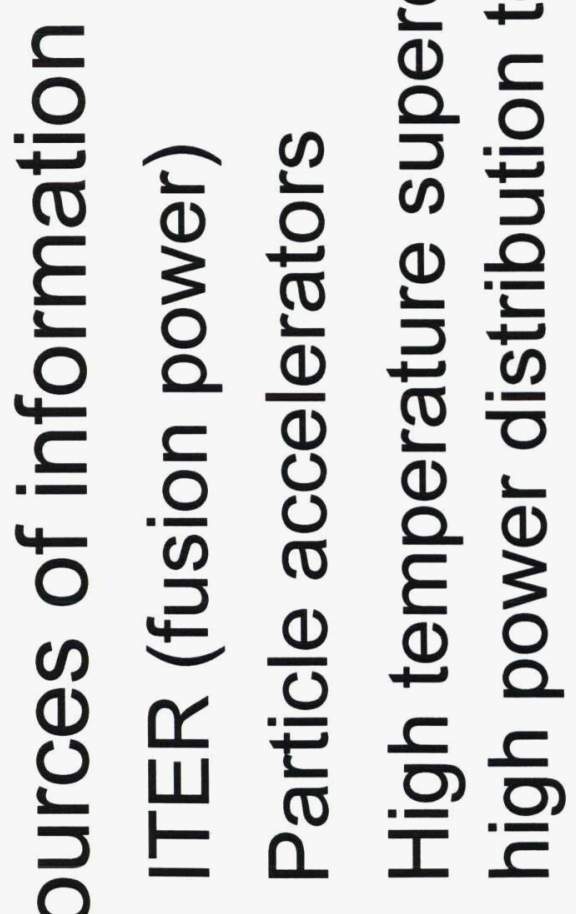

ऽ । । 


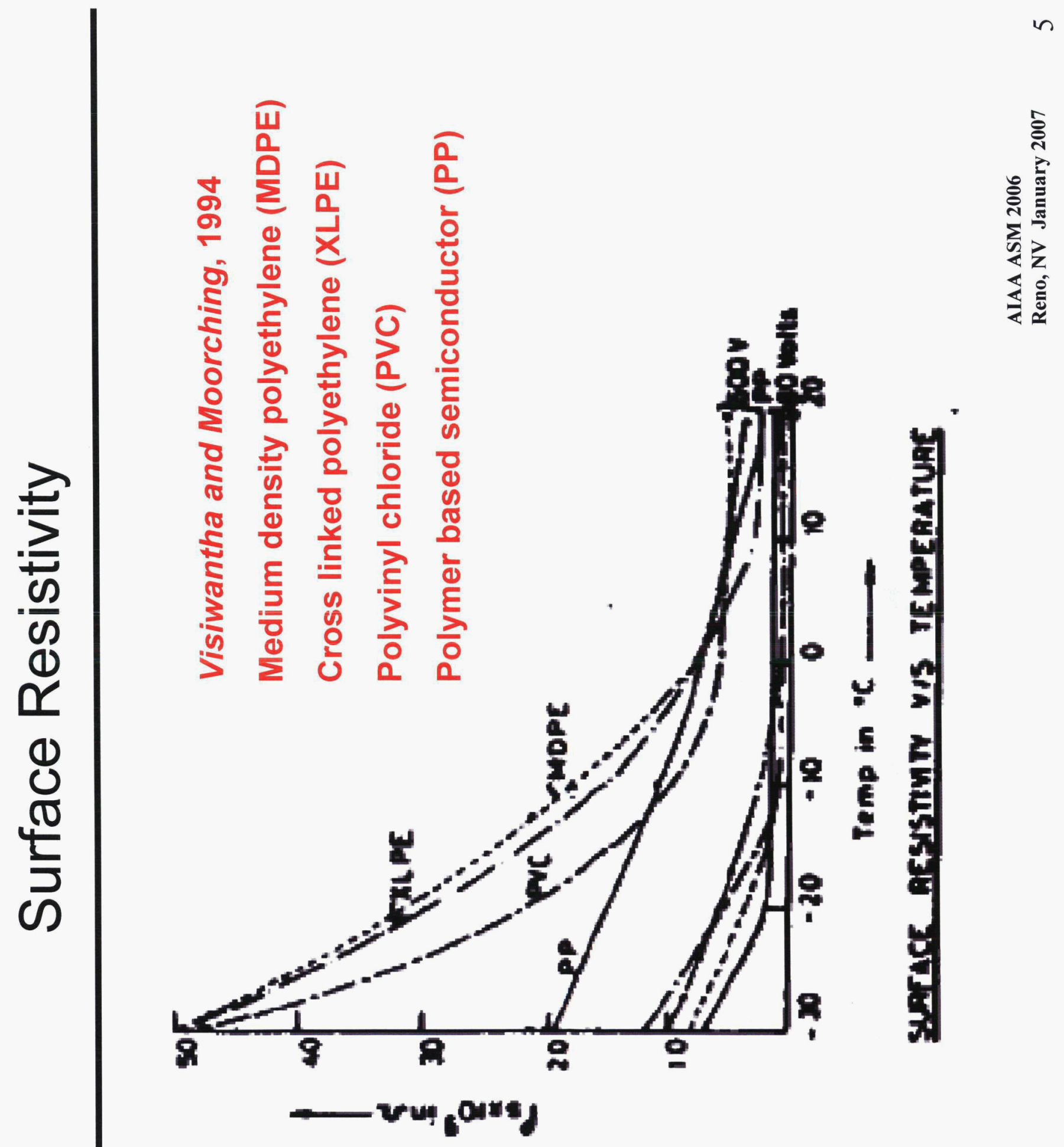




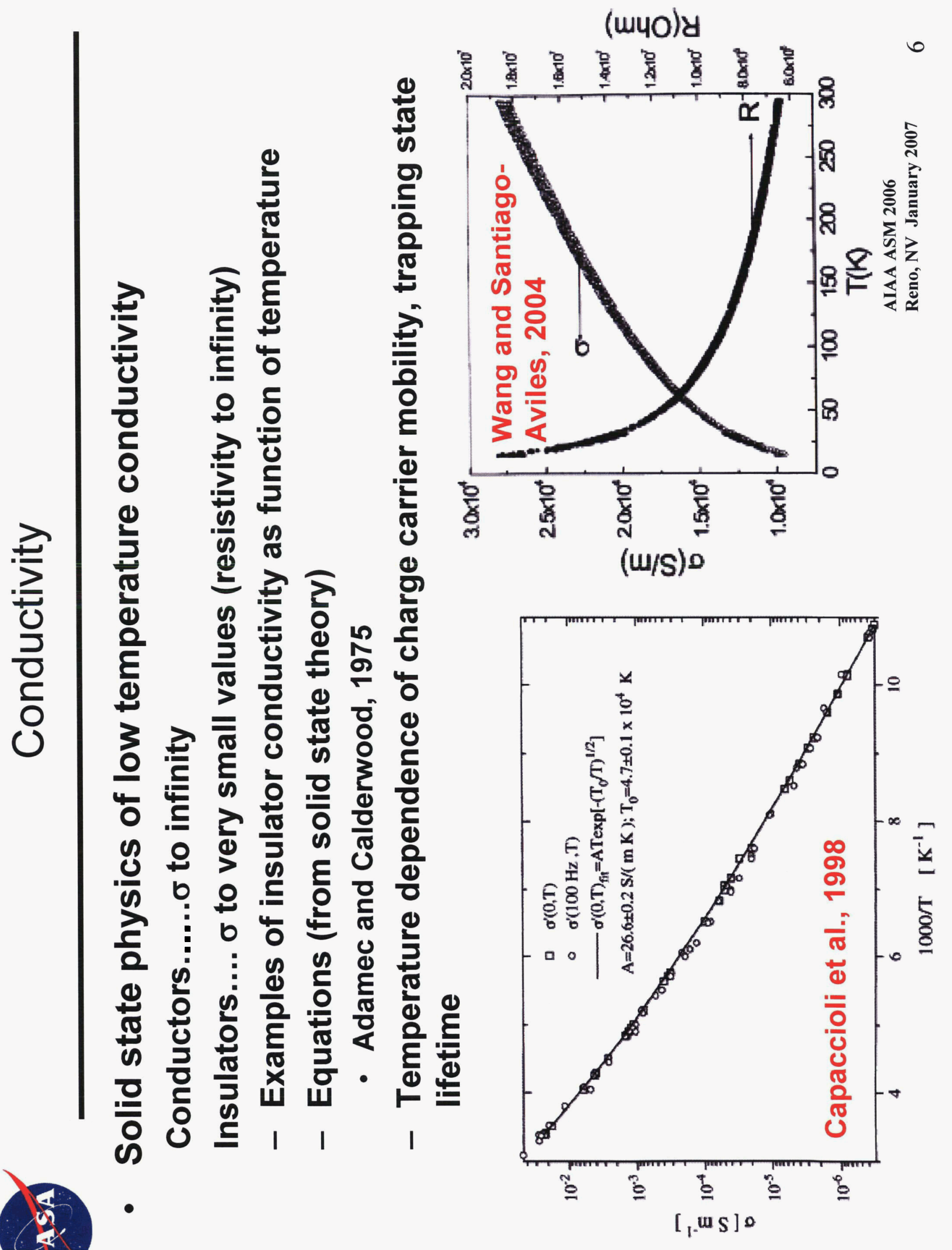




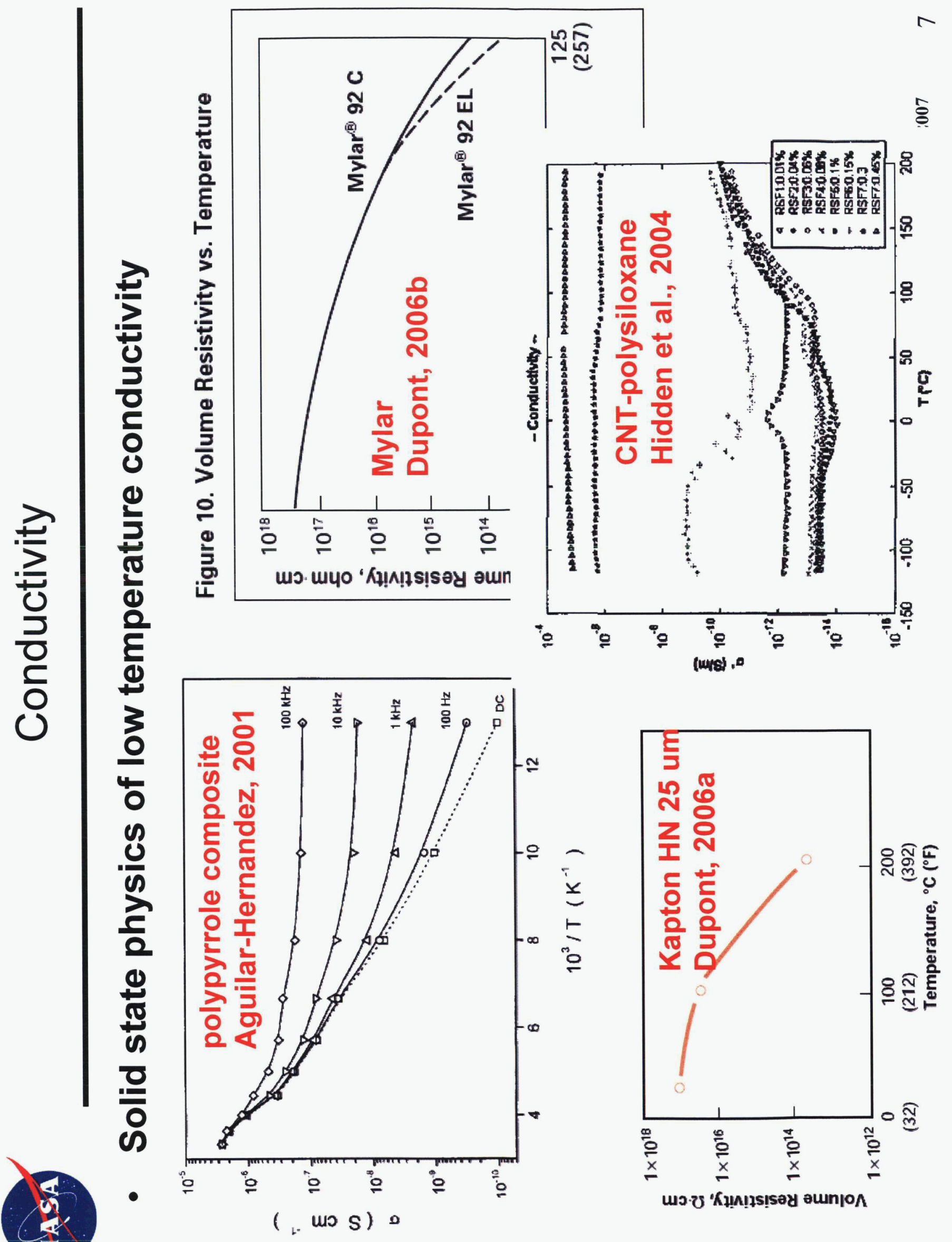




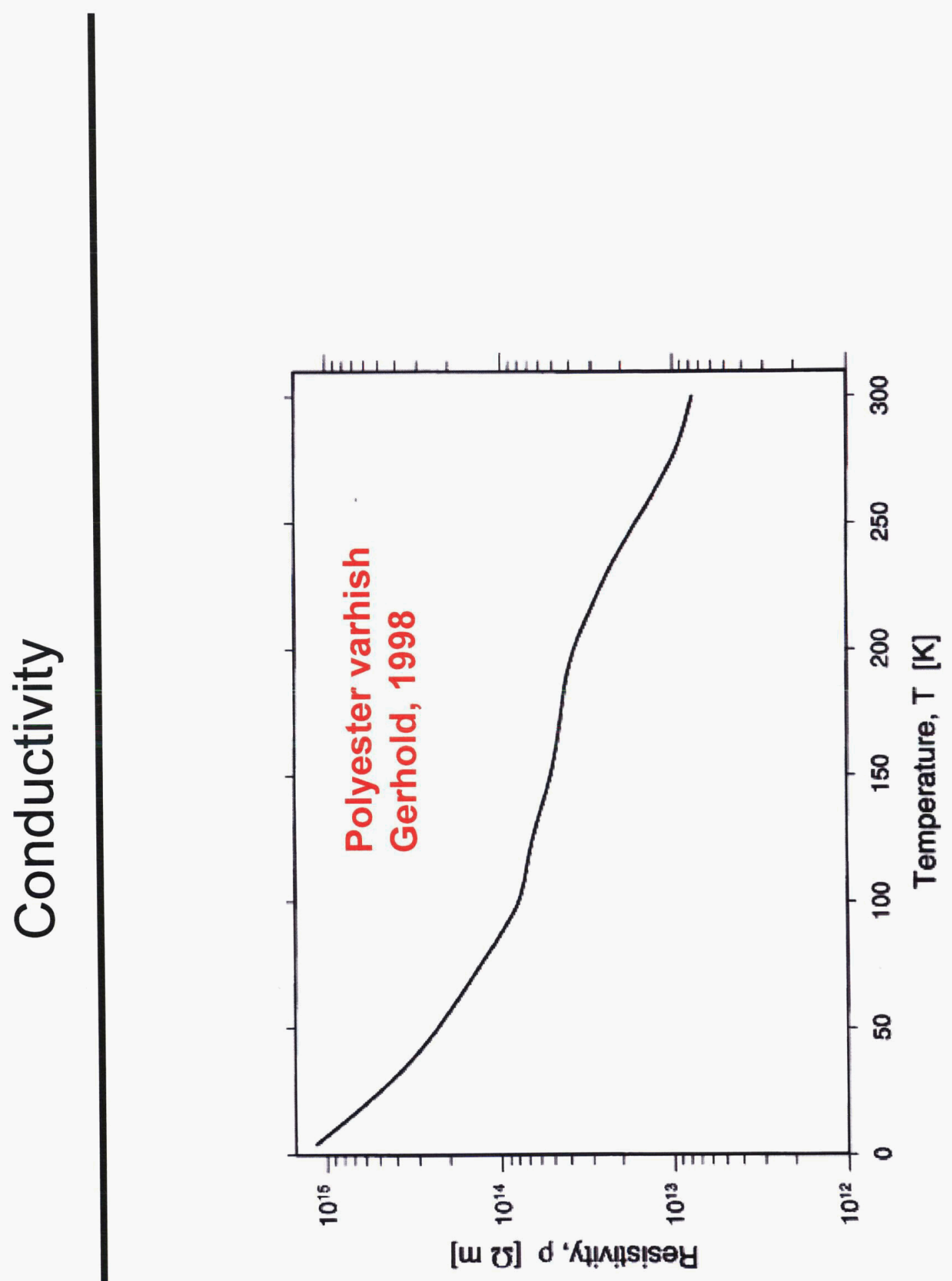




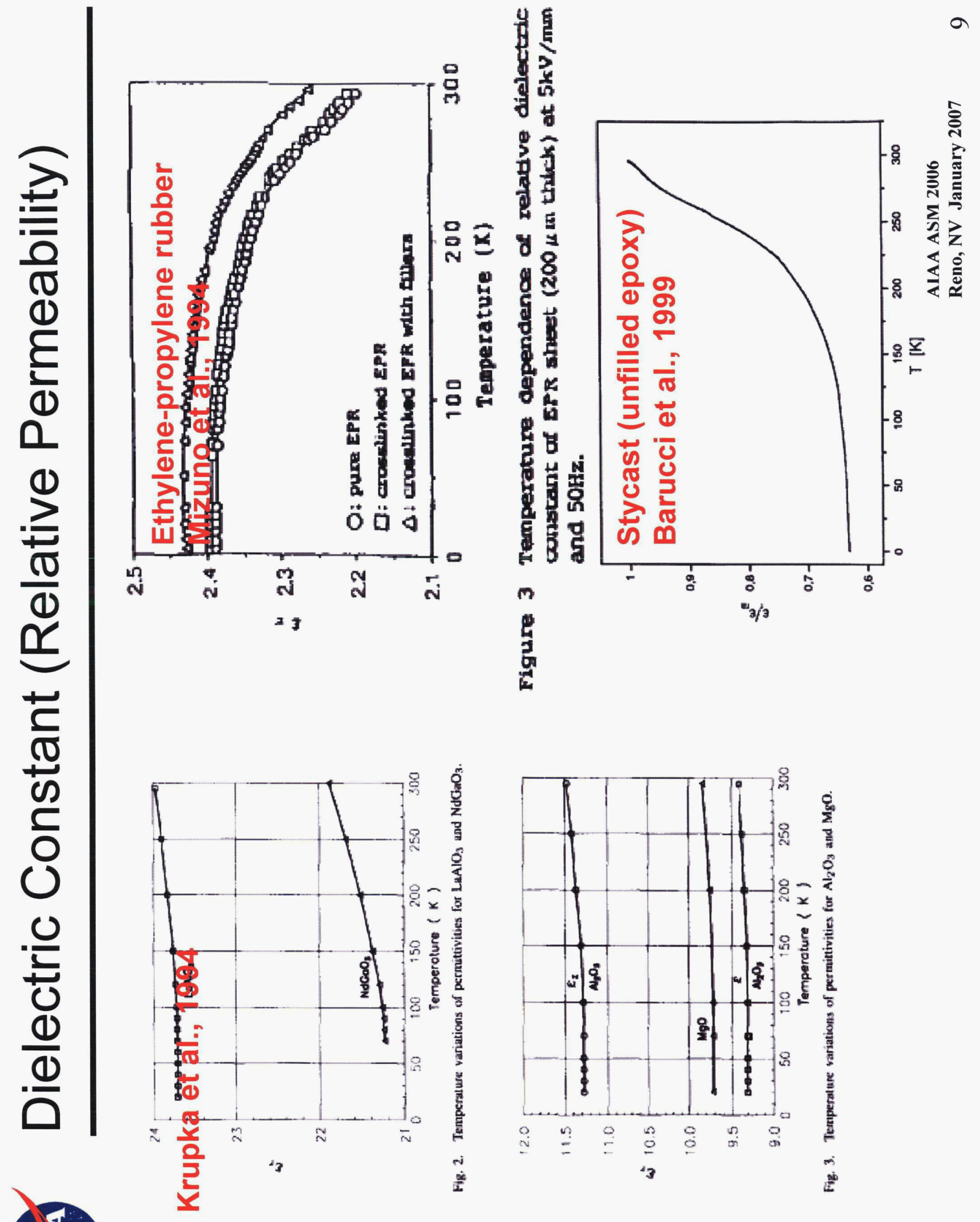


$d_{3}$

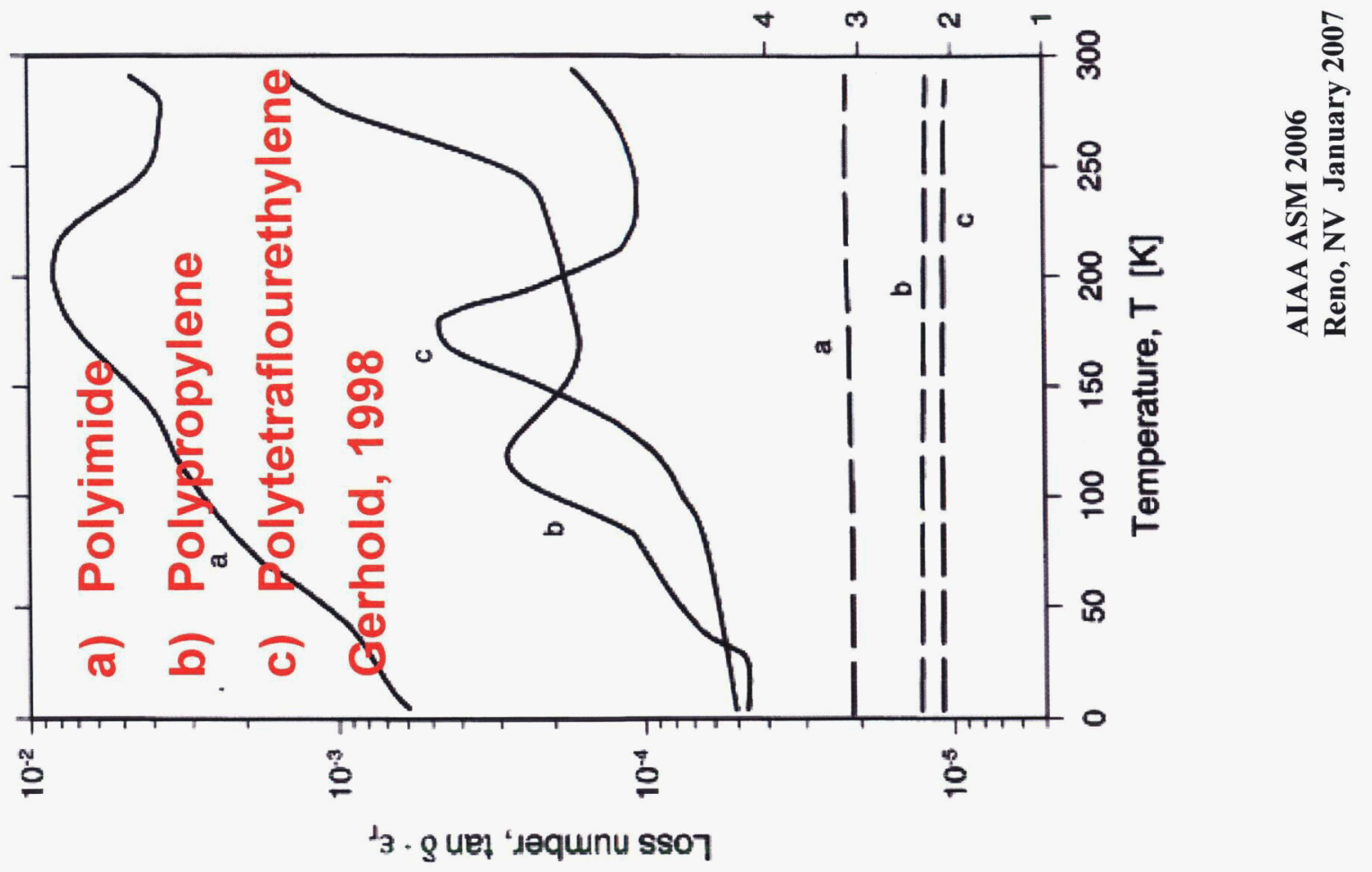

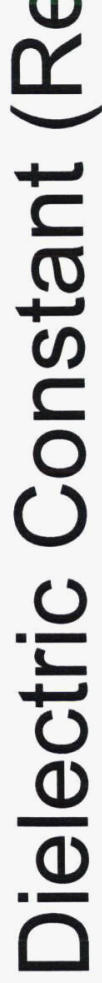

है

(1)

$\geq$

(ర)

${ }^{1} 3$ - $\mathrm{g}$ uet 'sequnu sso 7

E
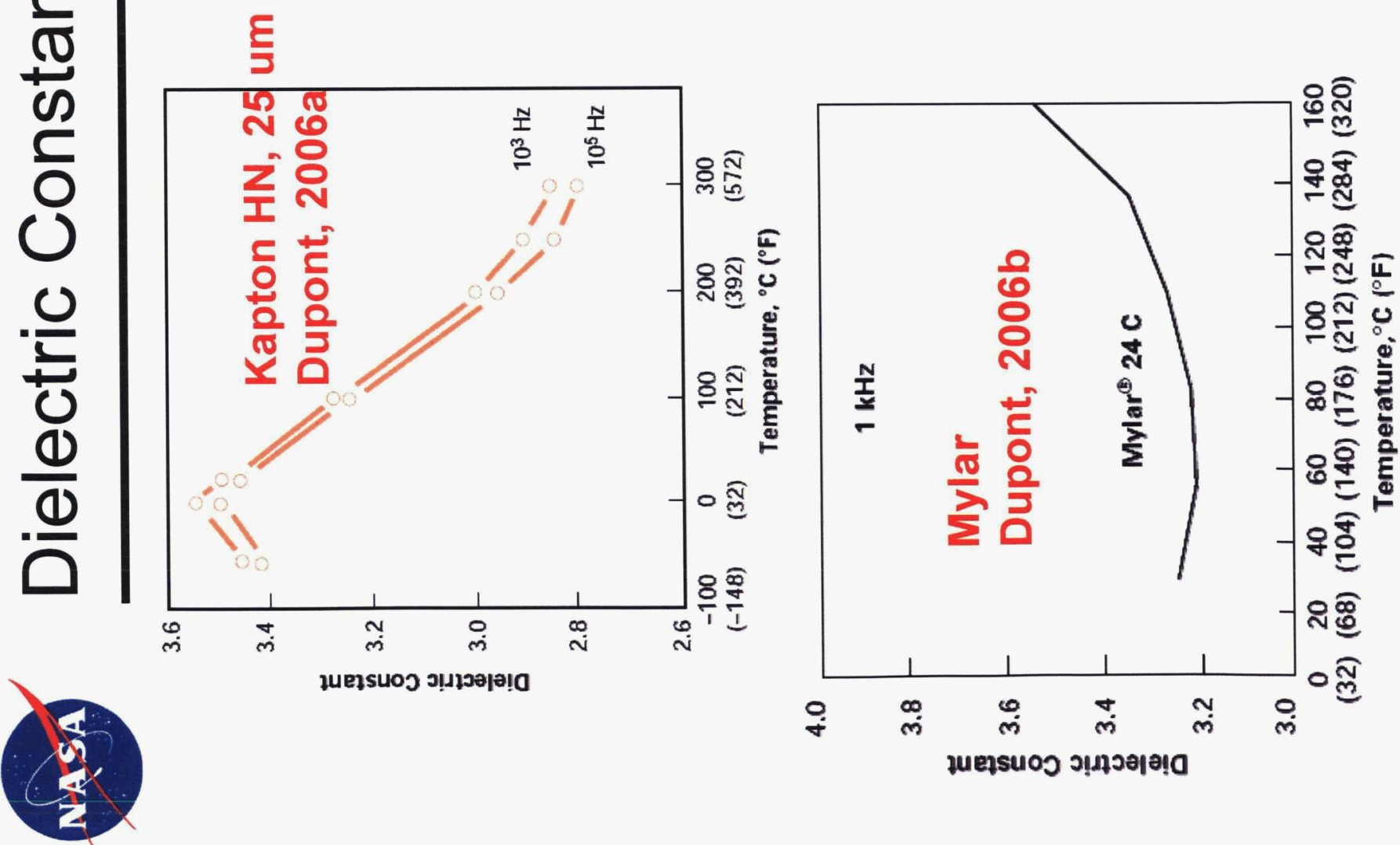


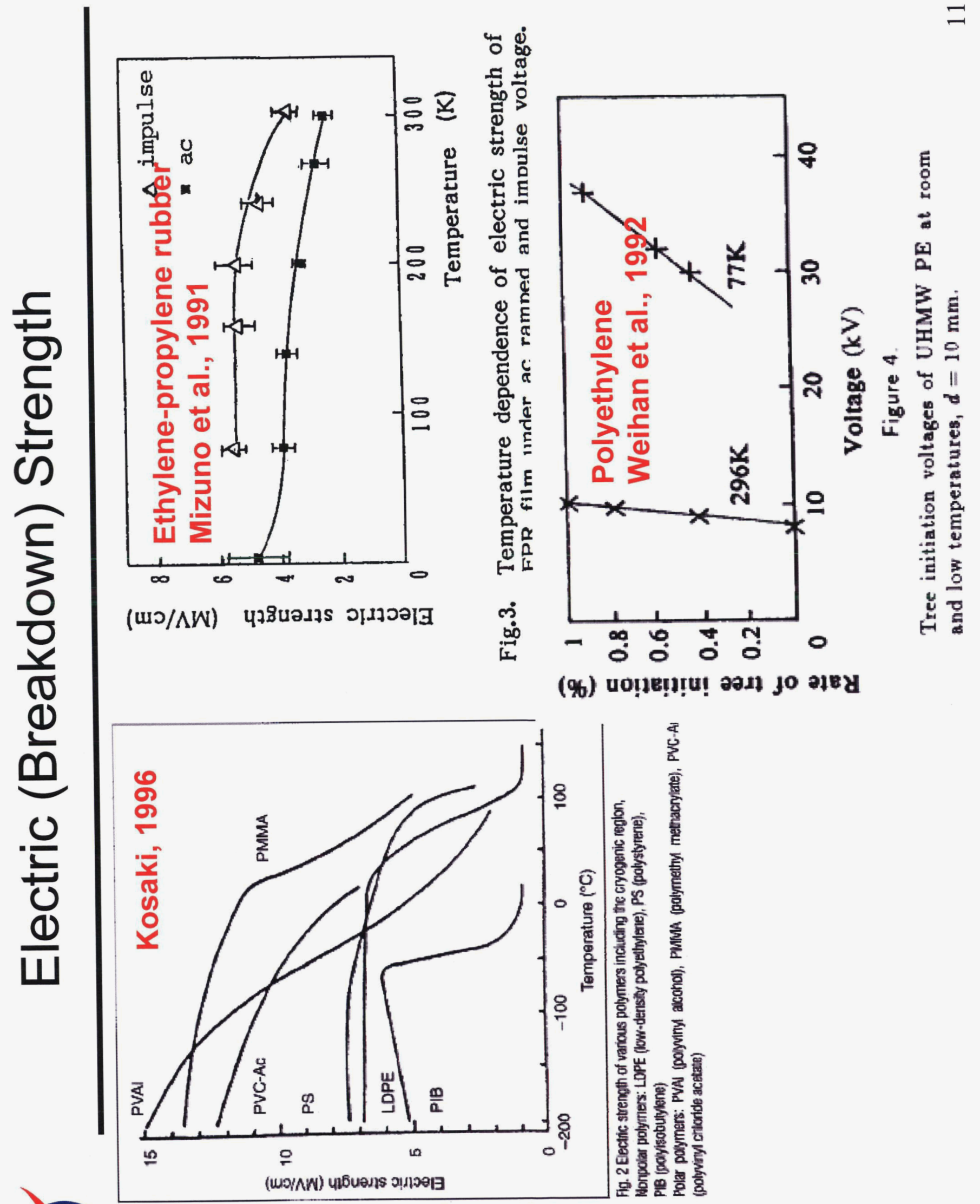




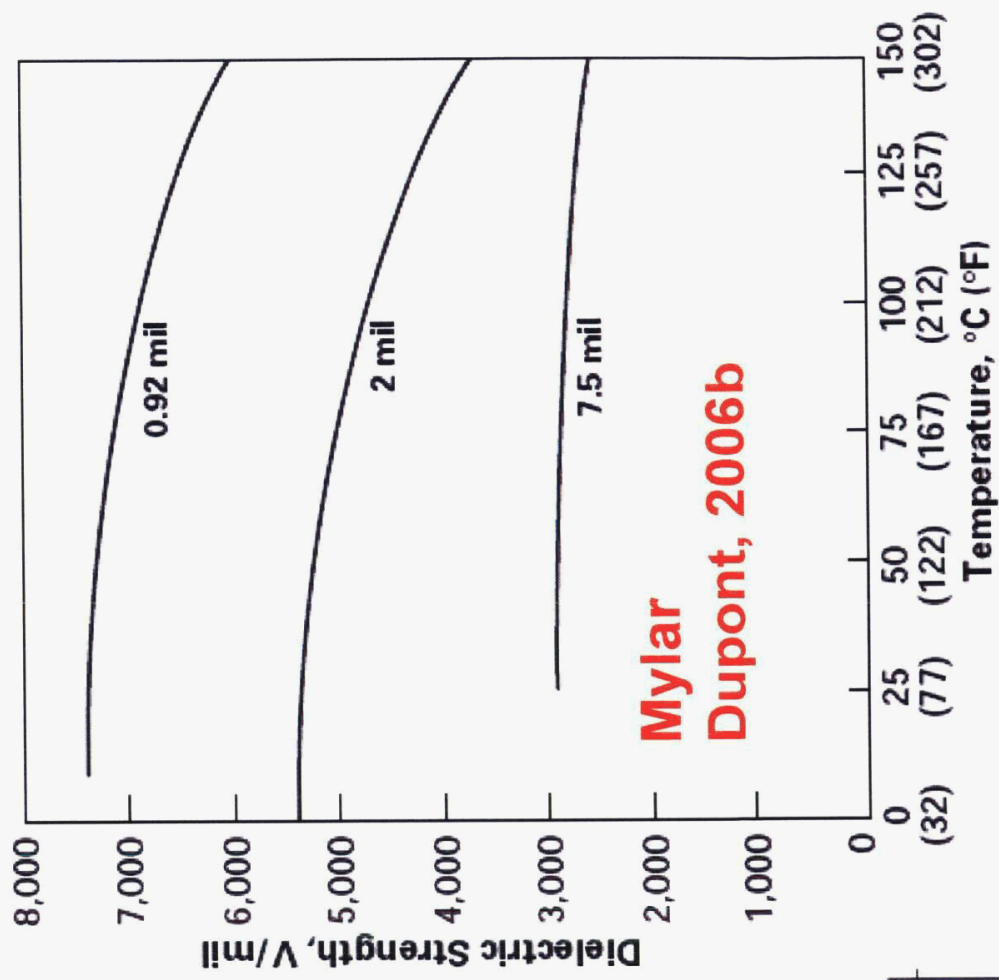

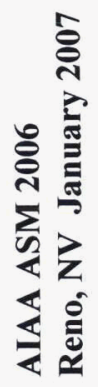

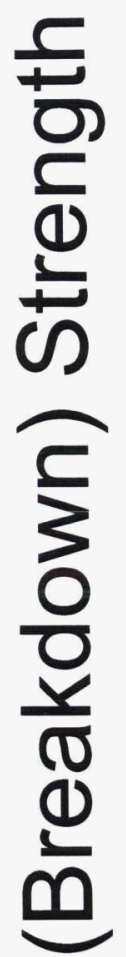

$\frac{0}{4}$

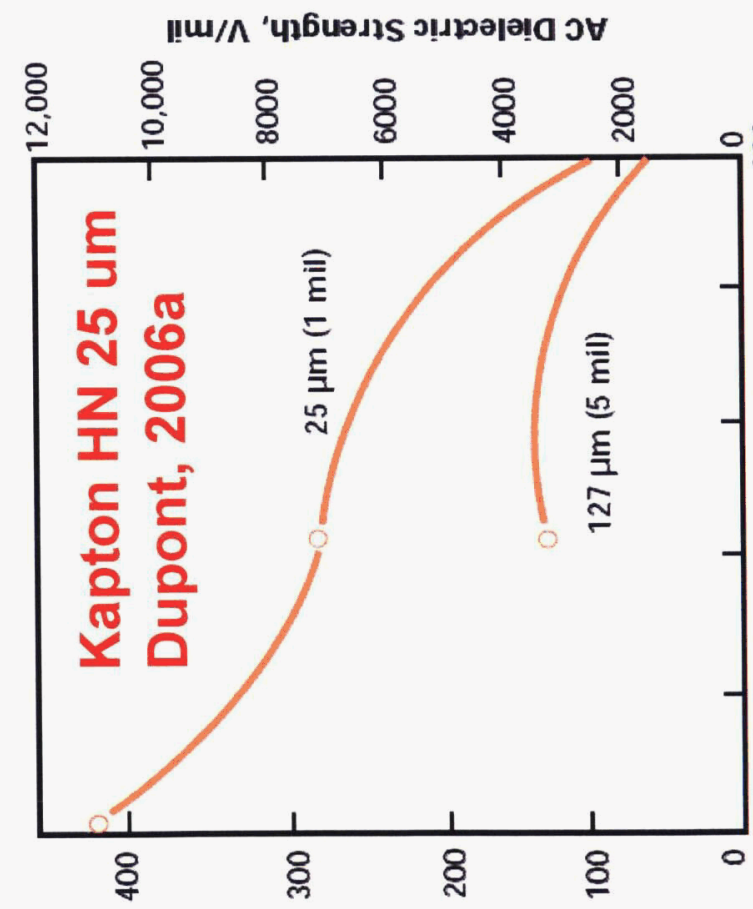

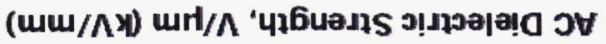

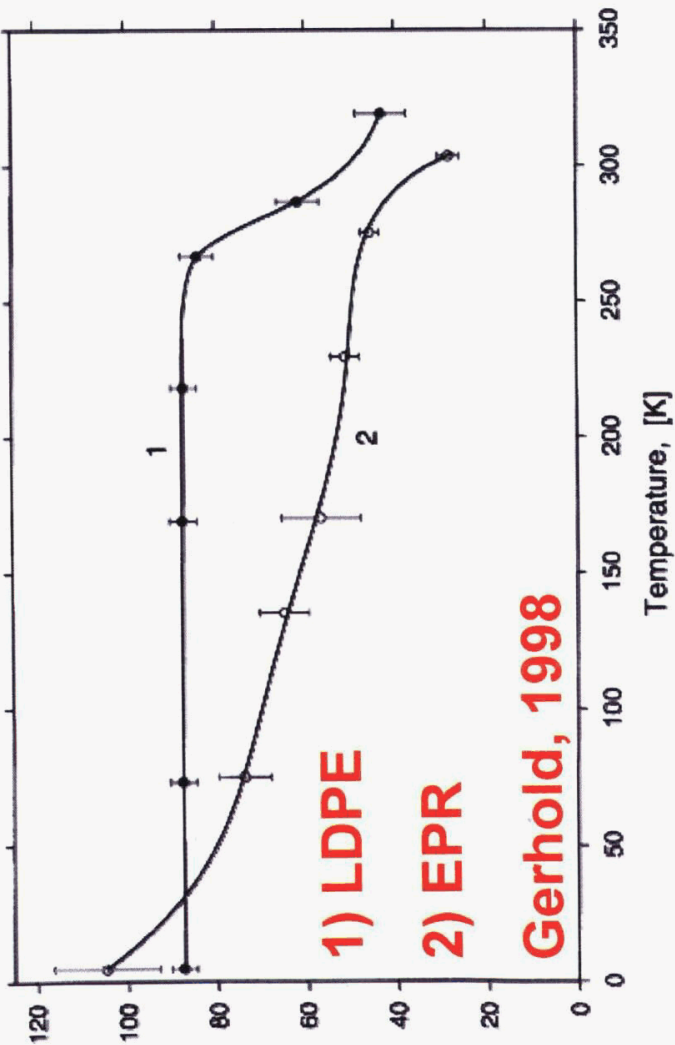

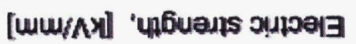

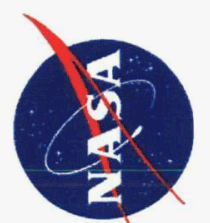



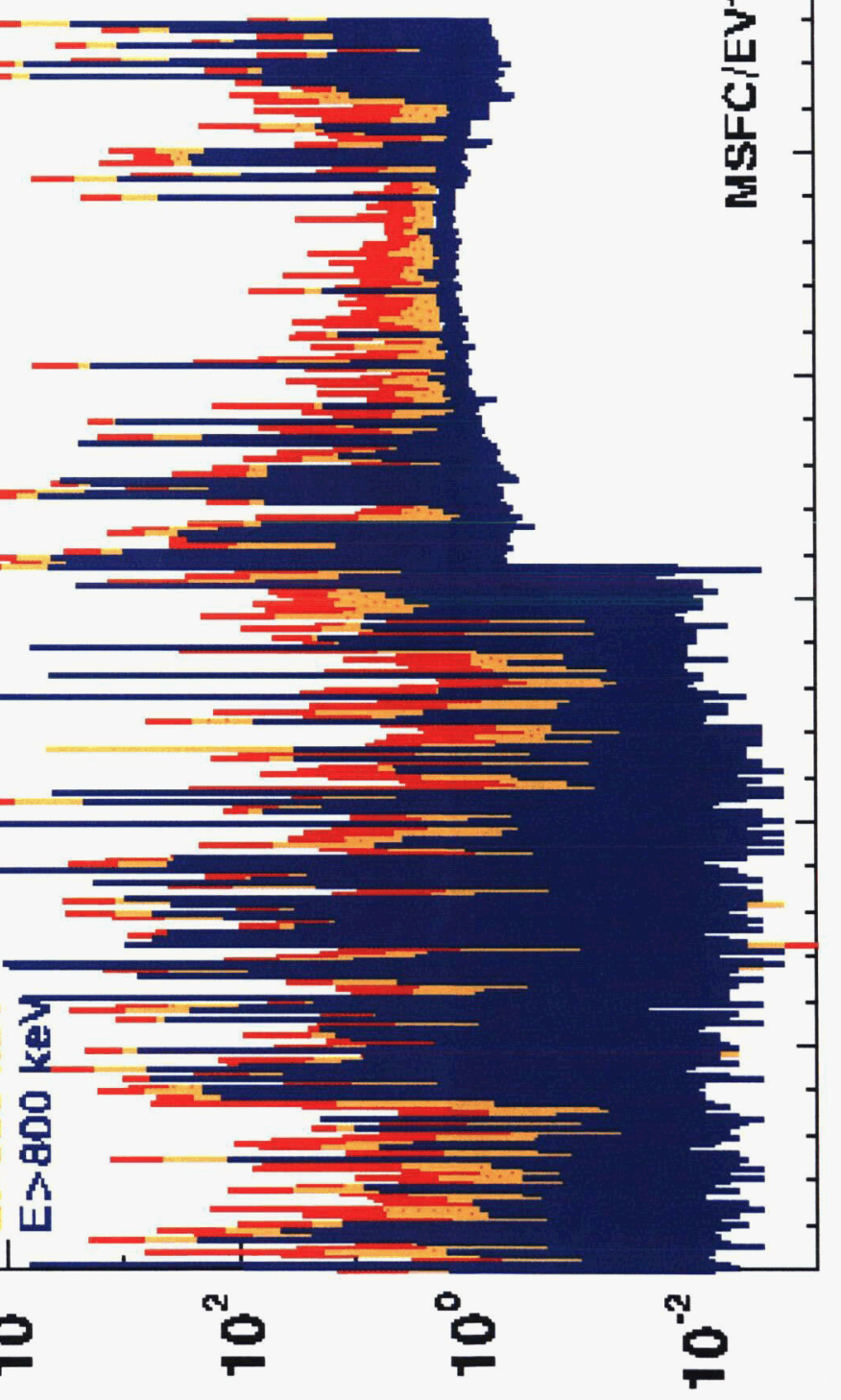

IP

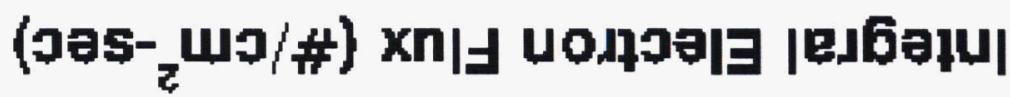




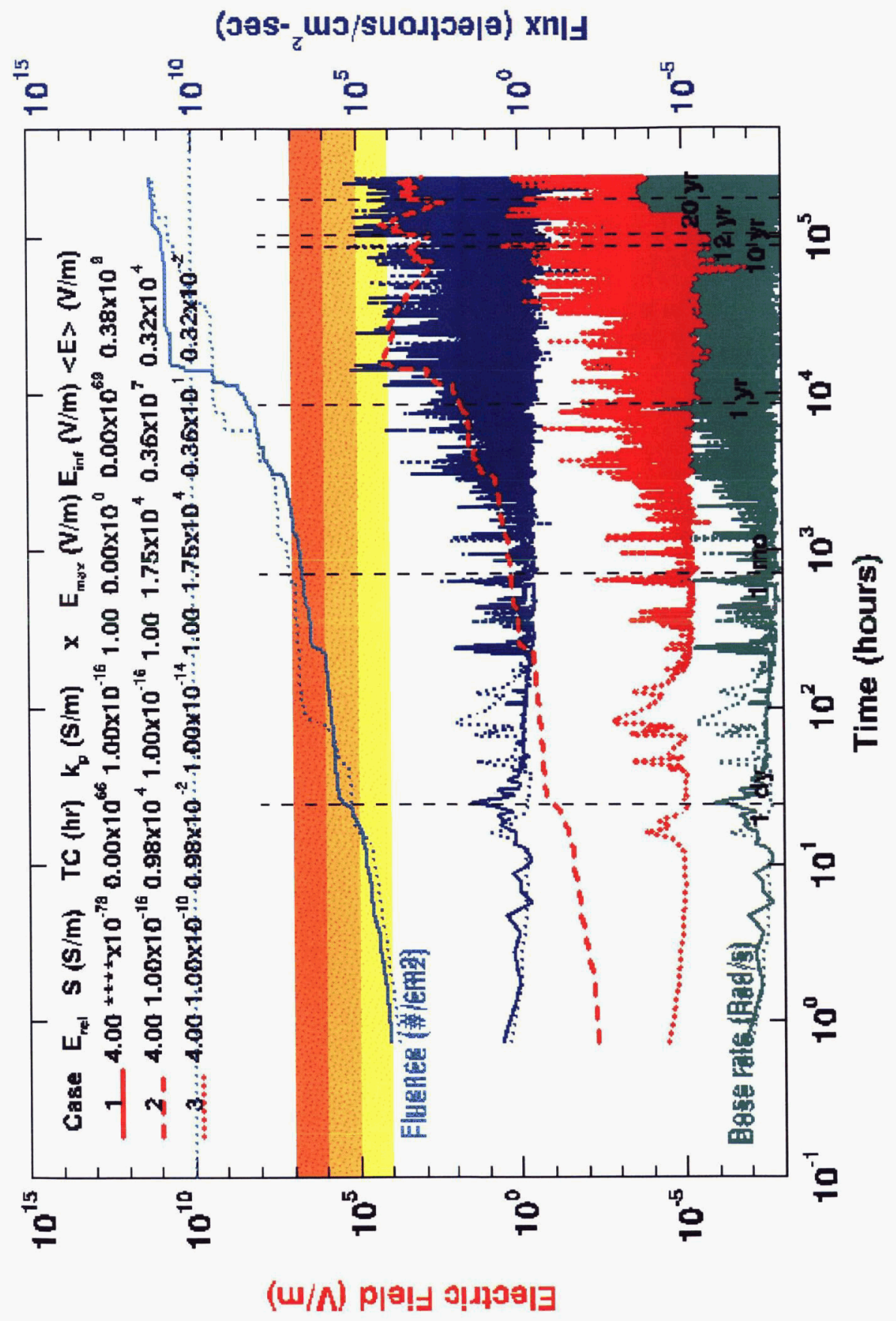




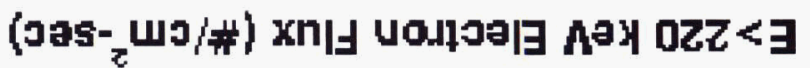

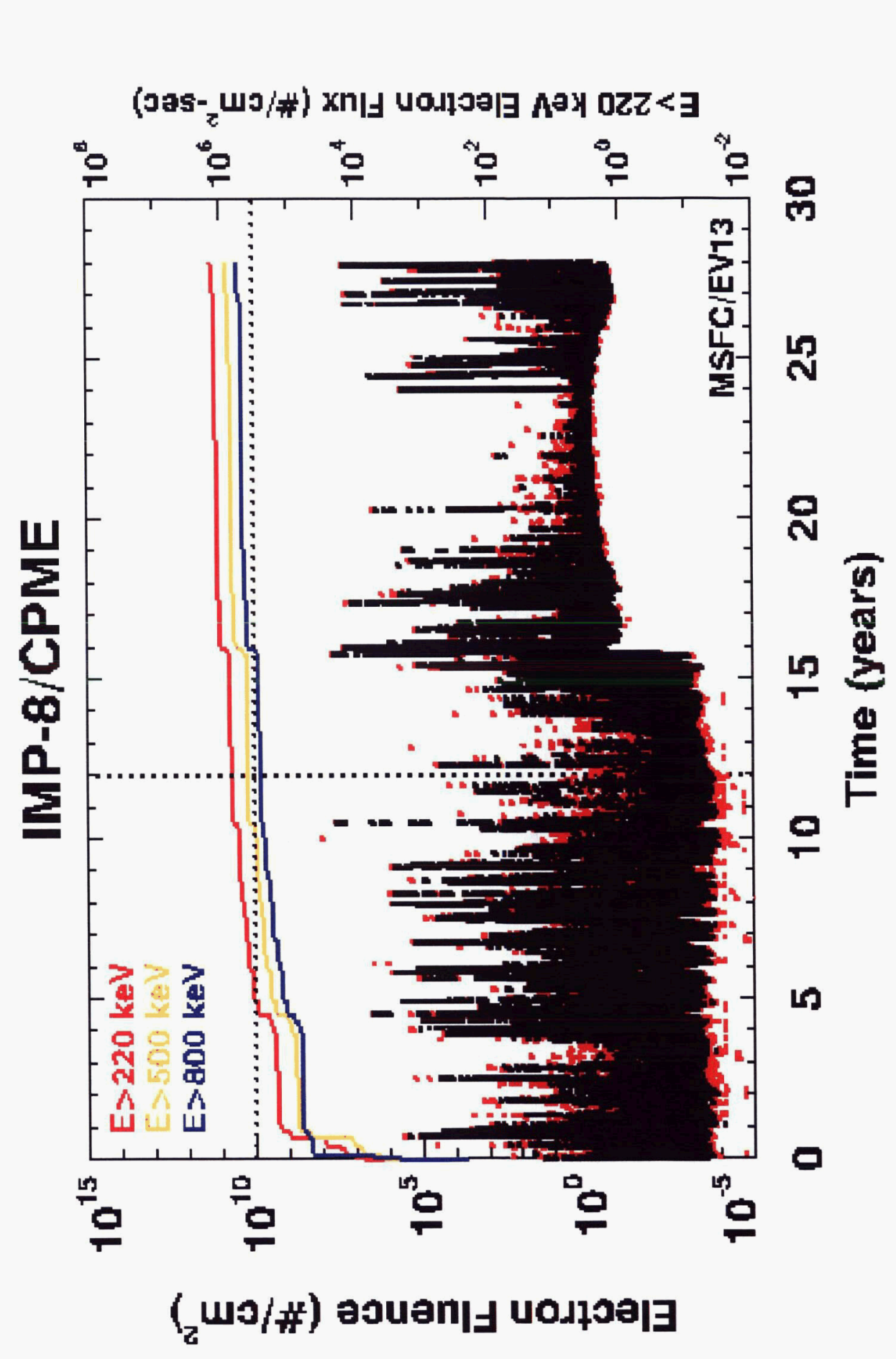

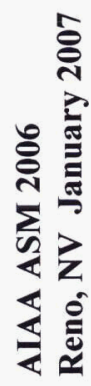



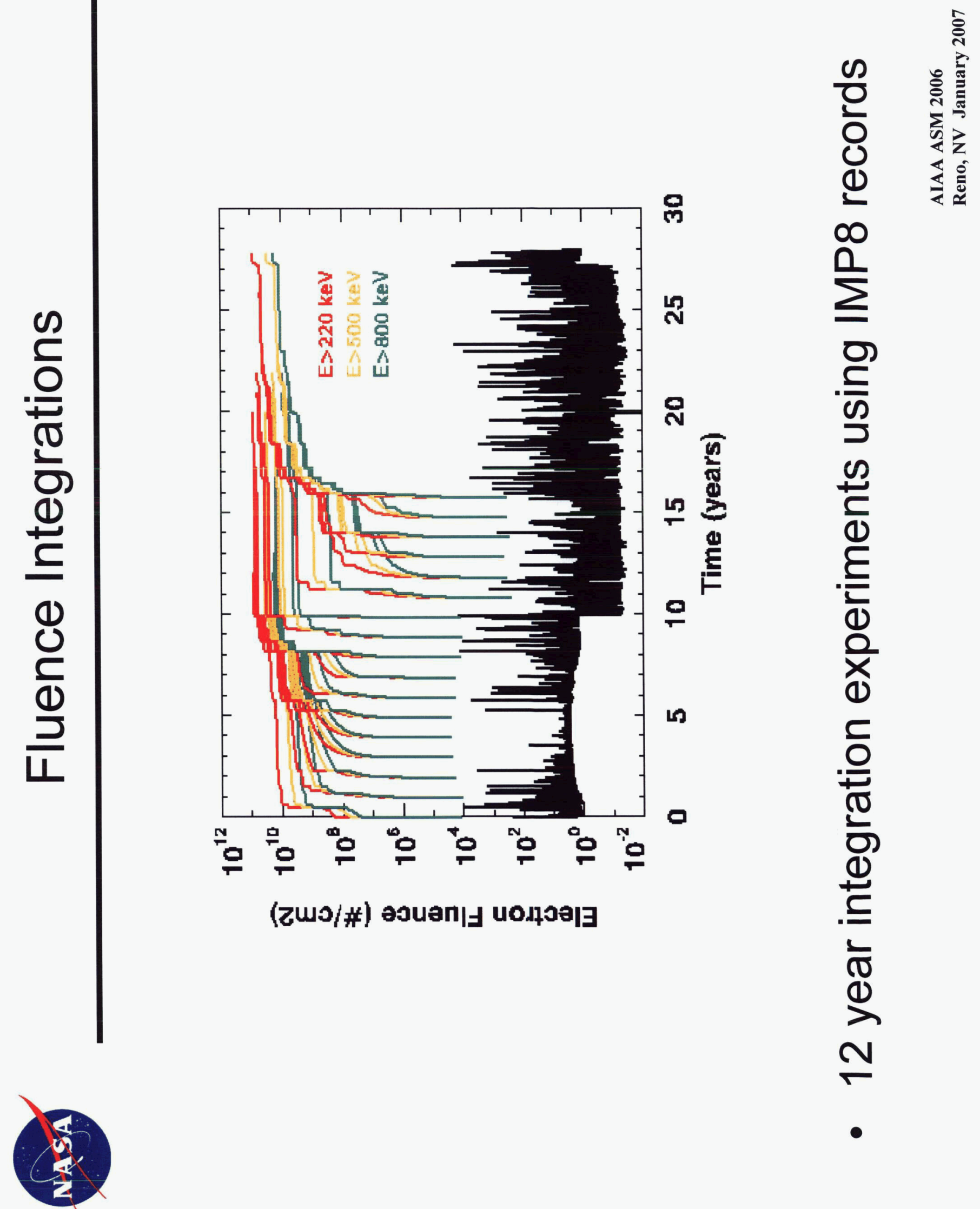


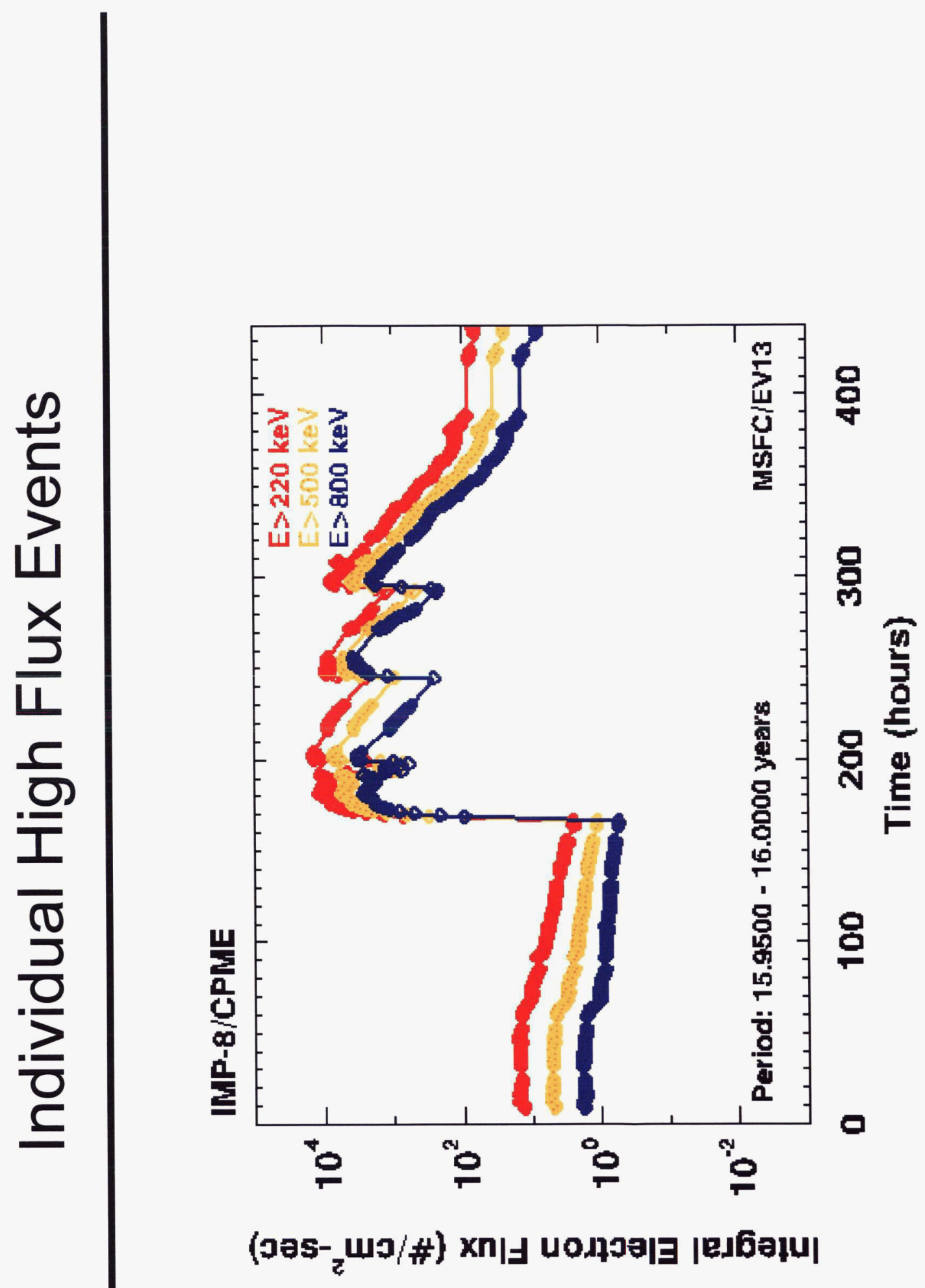




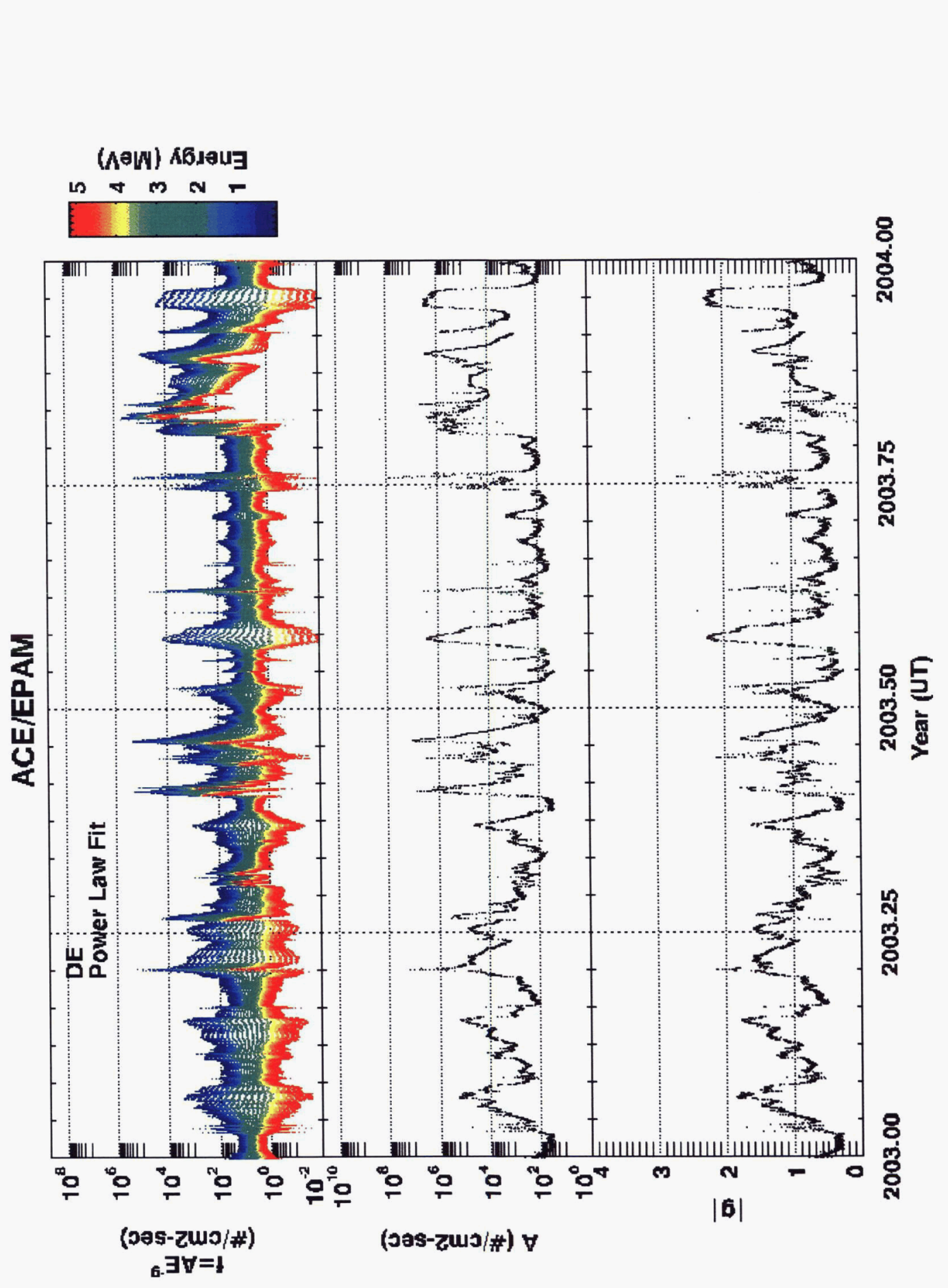

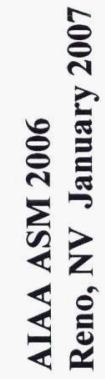

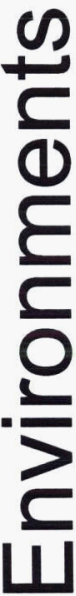

Ш

$U$

$<$ 


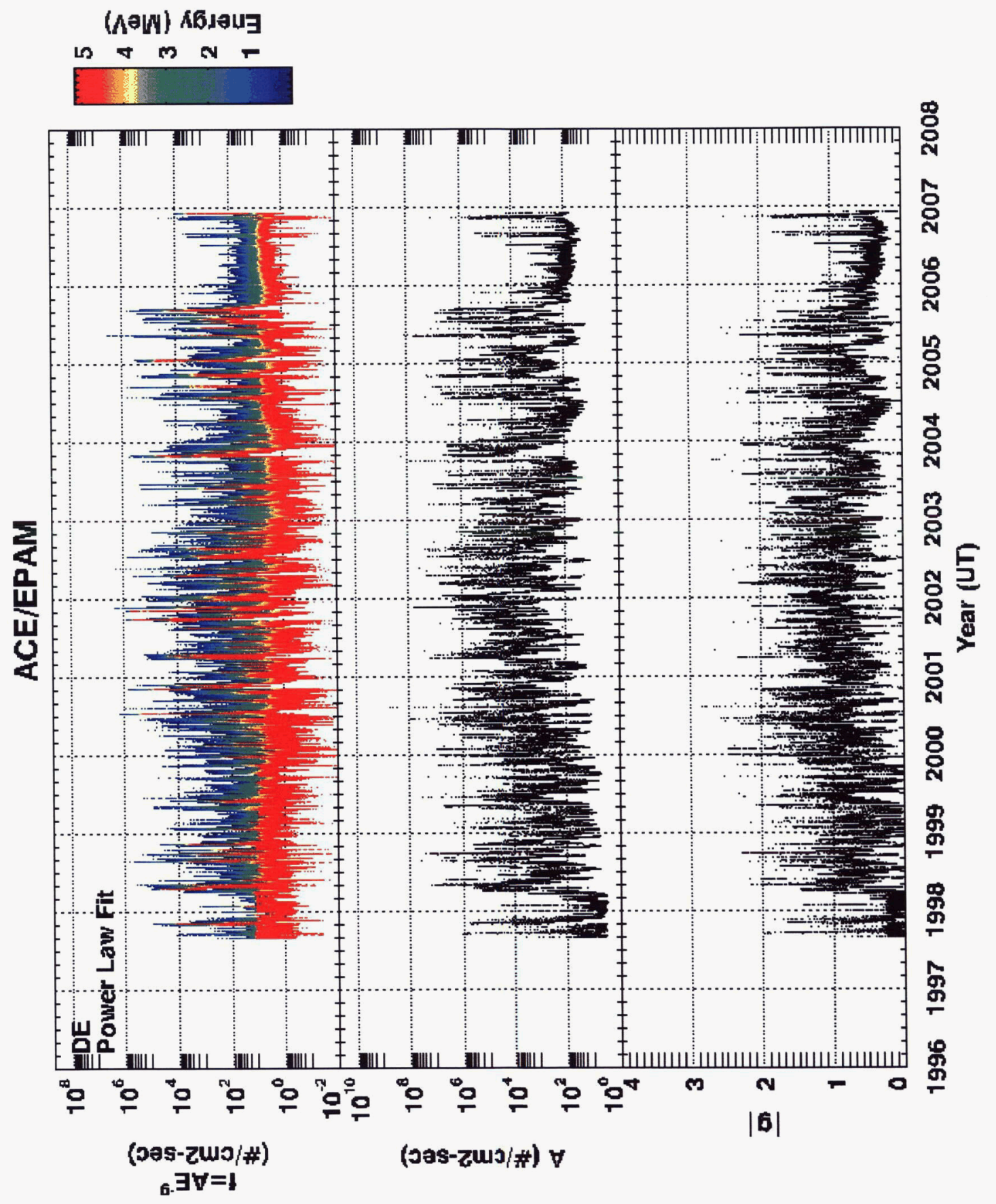



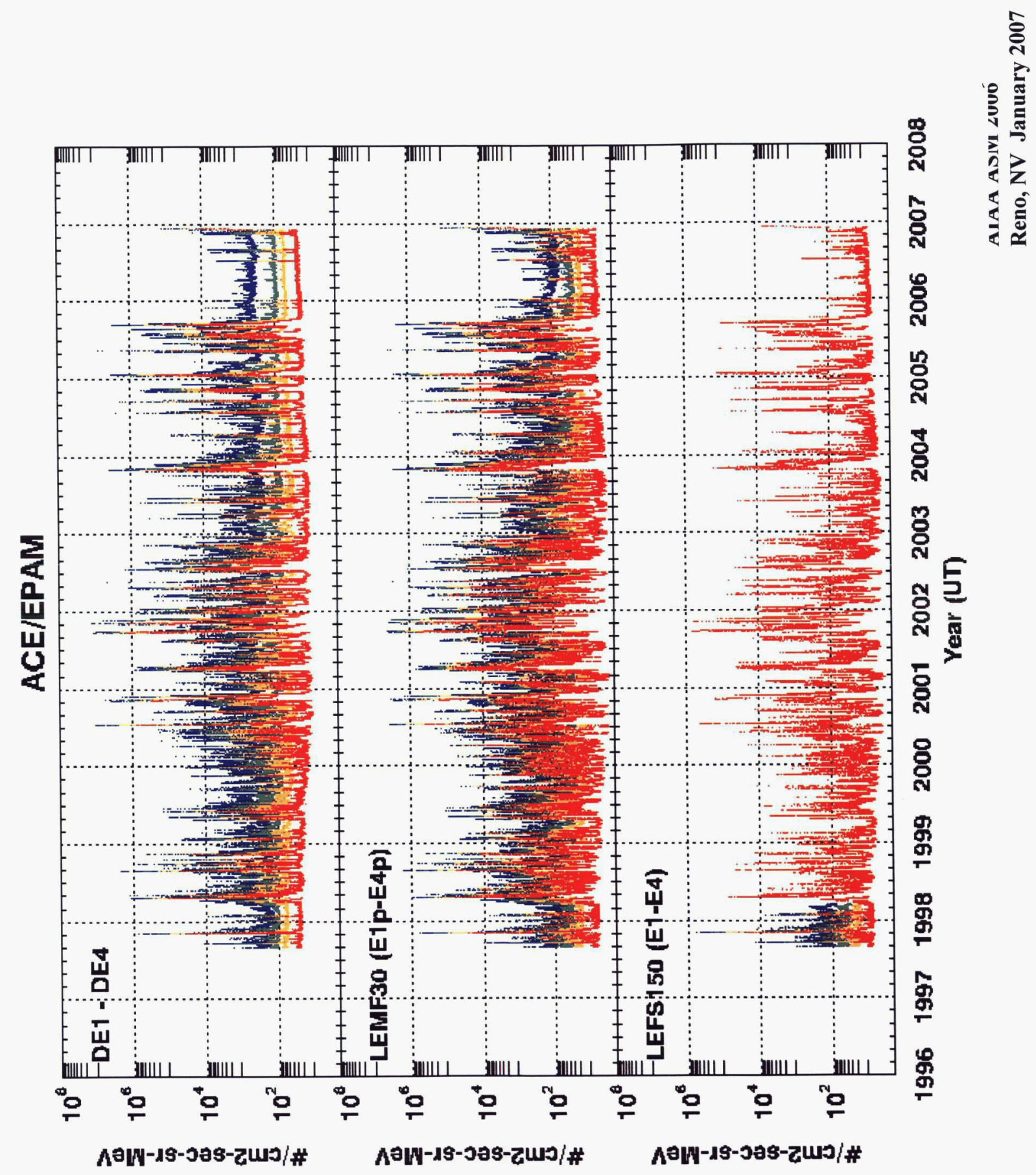


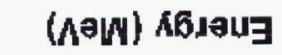

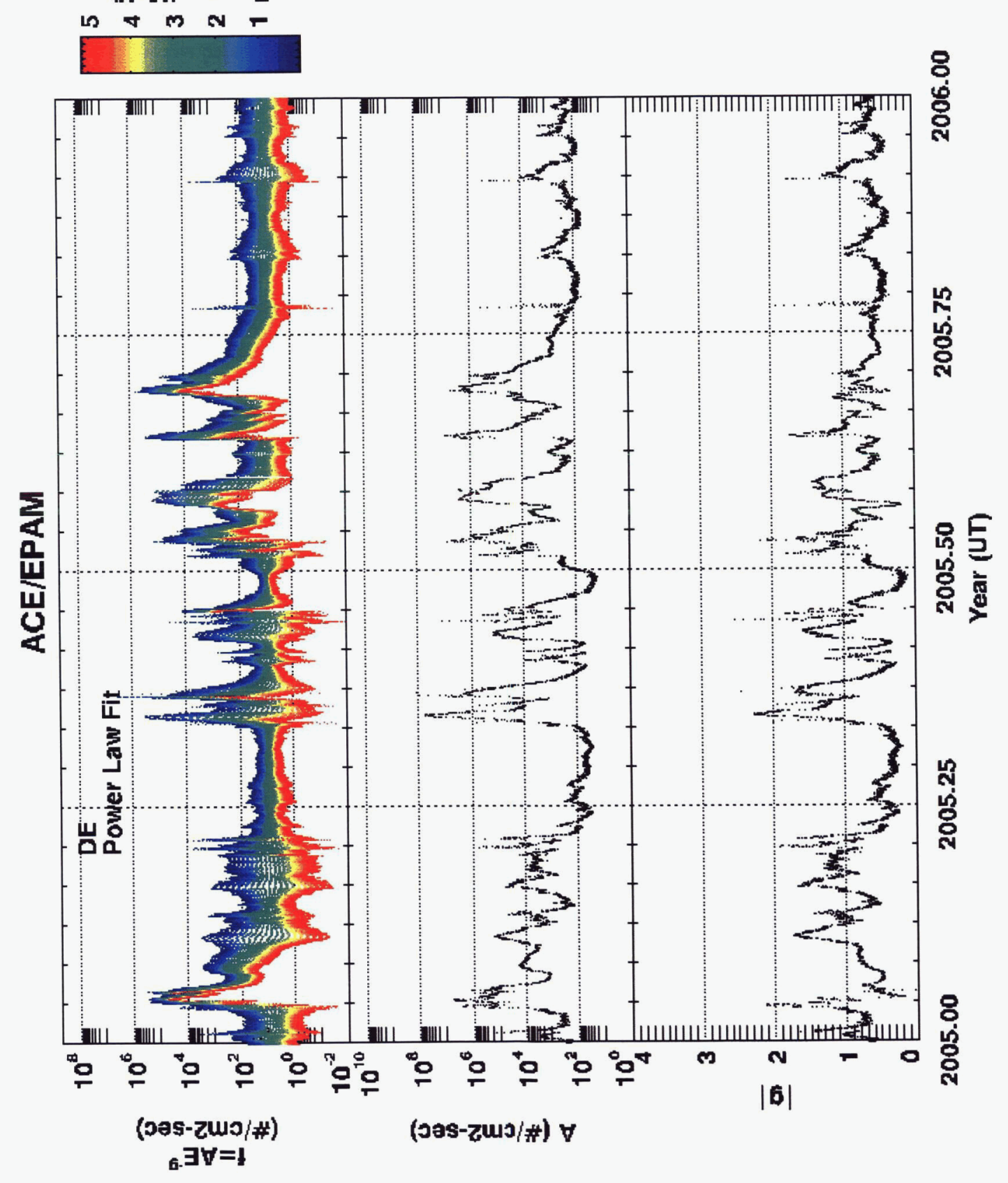

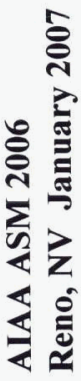

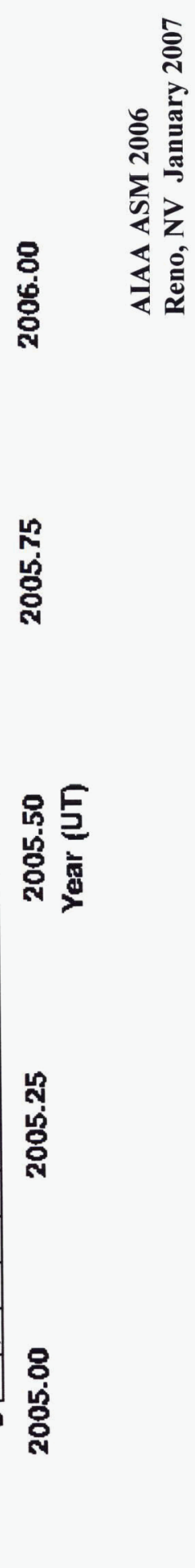


(A)

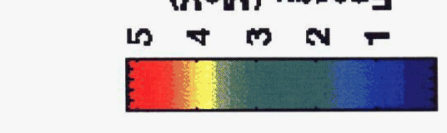

3
$\frac{1}{4}$
4

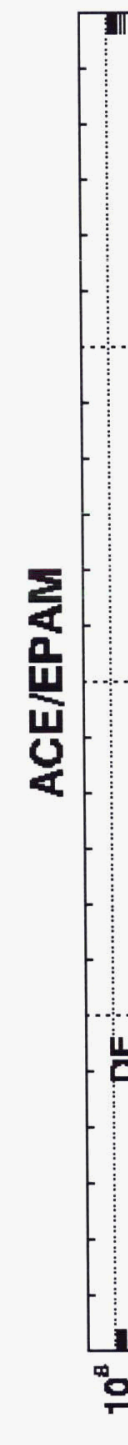

7

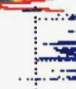

บ
IIII IIIIL I I IIII

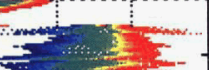

(1)

를

Ш

U

$\varangle$
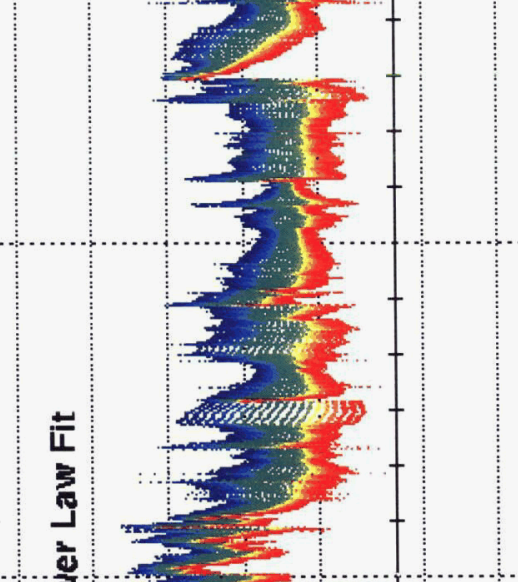

$\lim _{1}-1$
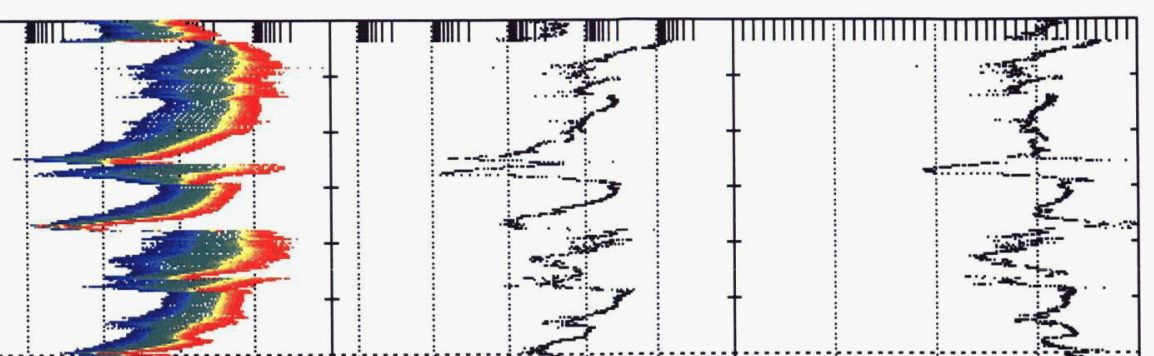

옹
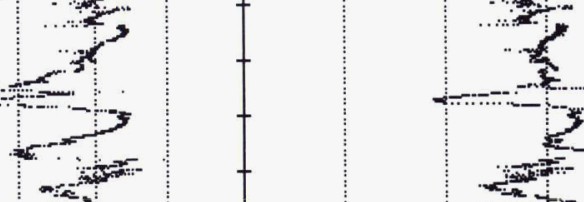

$\rightarrow$

$\rightarrow$

an
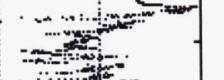

in
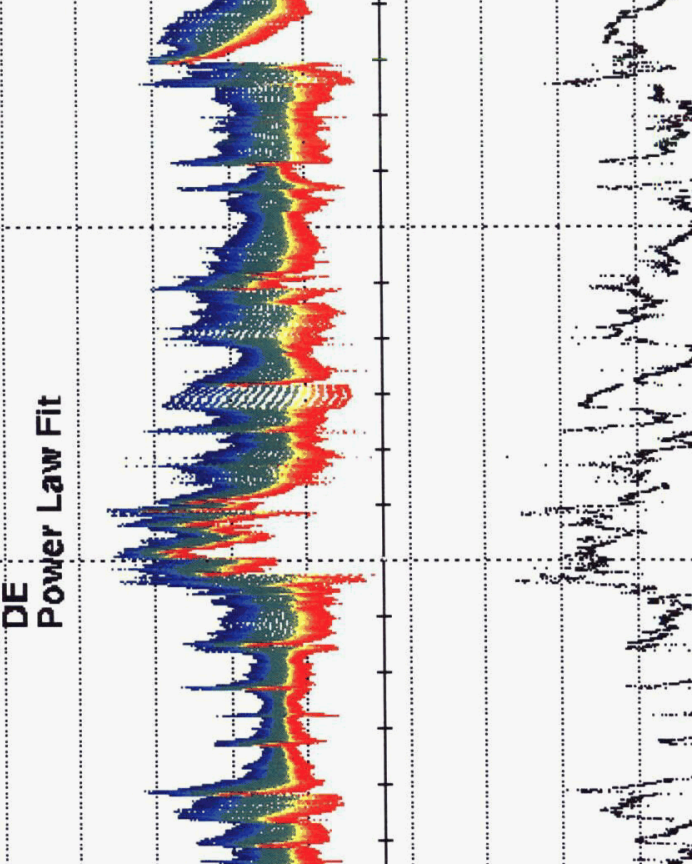

III III INt

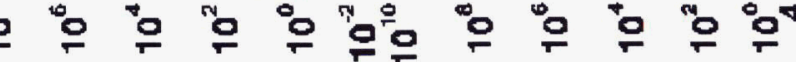

(oas-zWo/\#)

6. $\exists \forall=!$ 


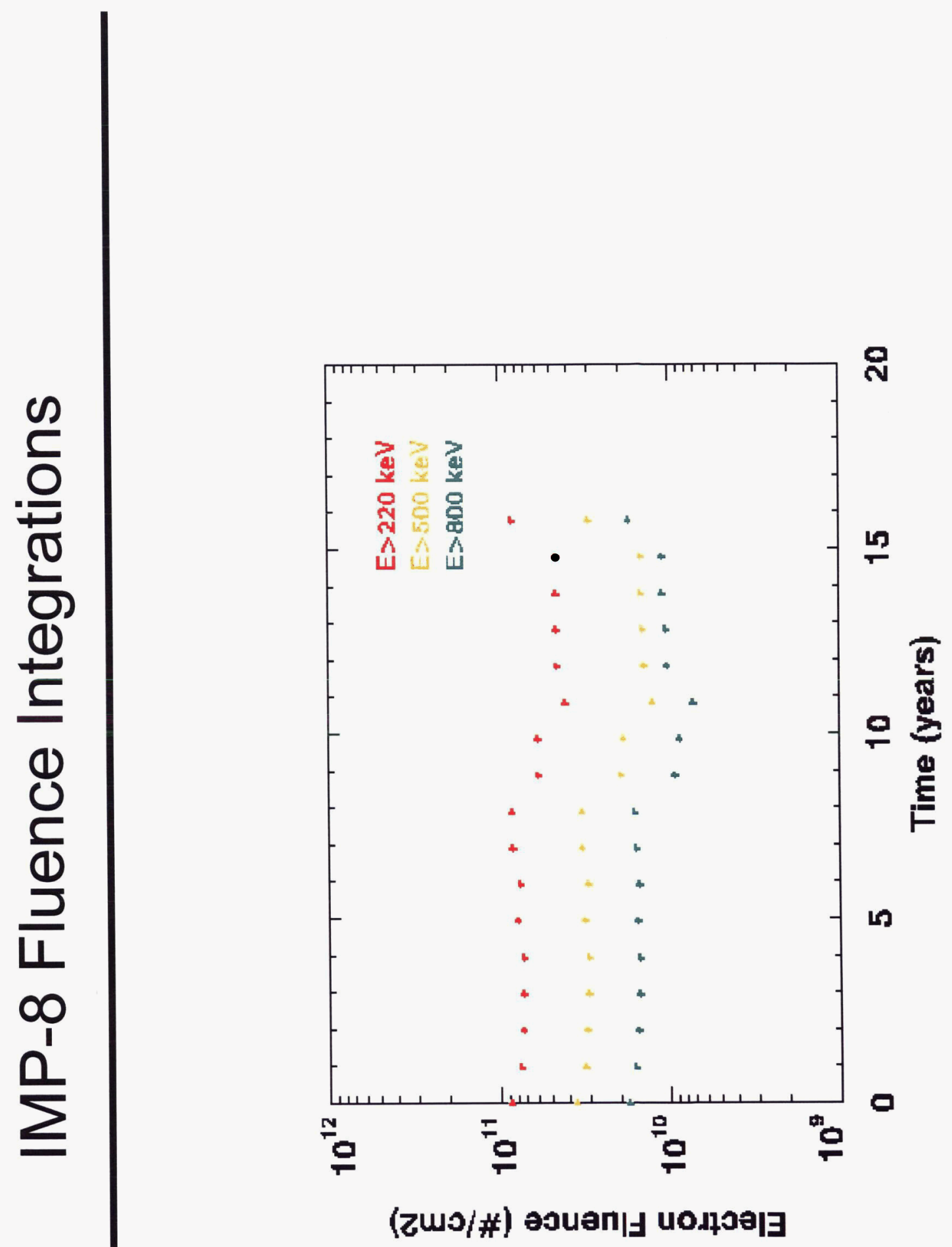

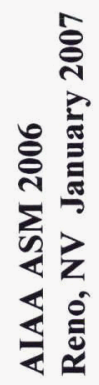




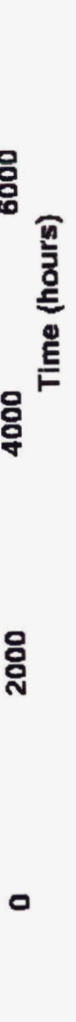
(oes-zWo/\#) H (oes/pes) ip/6p (wo/s) puos $(w / N) \exists$ 


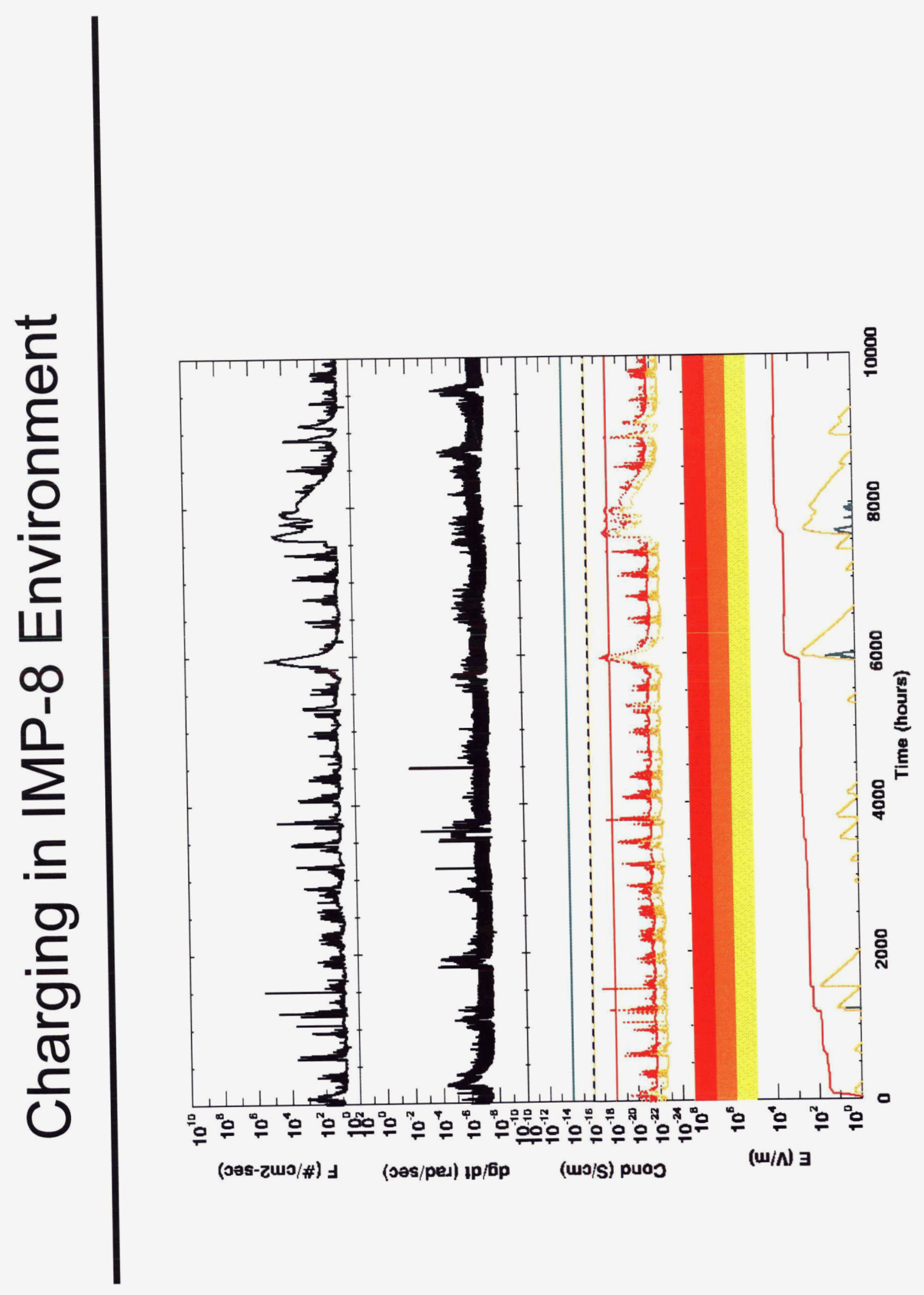


i

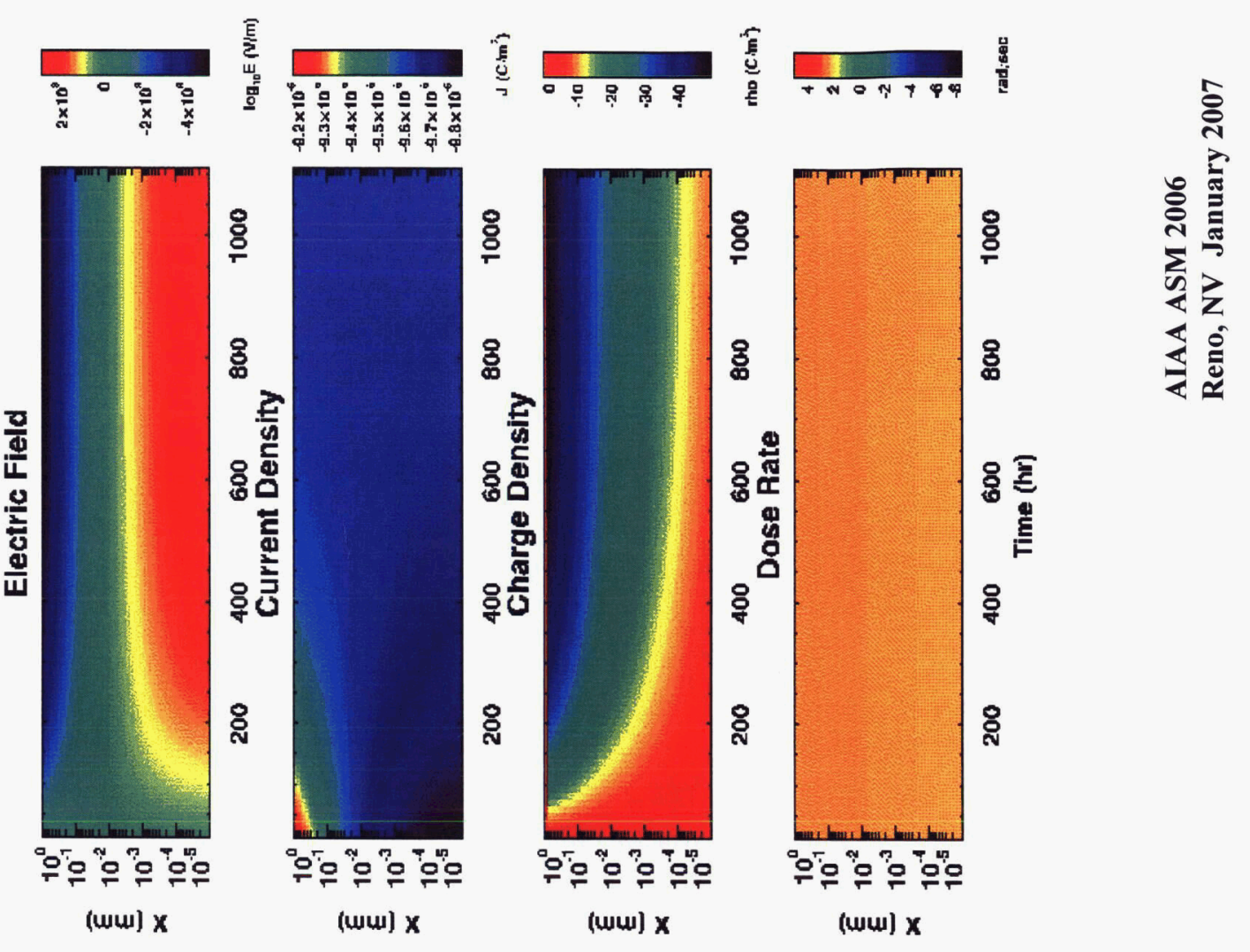

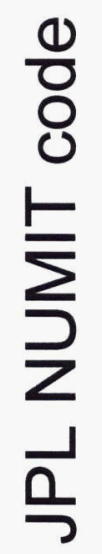


0
0
$\frac{1}{0}$
0
0
0
0
$\frac{1}{0}$
$\frac{1}{0}$
$\frac{\sigma}{0}$

ס

$\frac{1}{\sigma}$

䎛

을.

¿⿳亠口冋.

18

을

은 딘

ปั

잉

(1) है

ํํㅇ

त 8

으

을

है일

$3 \frac{0}{5}$
N

$\frac{E}{0}$

응

등

(1) 인

(1) (1)

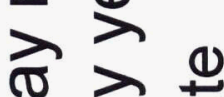

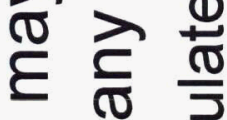

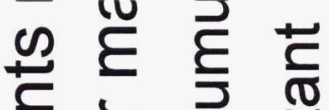

는

튼 이을

됴 을

$\geqslant$ 믐

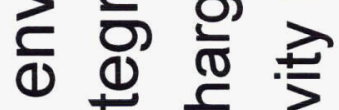

$>$ 드 인

究:

志 을 을

을 $\frac{\pi}{3}$ ह

(1) 0 ल छ

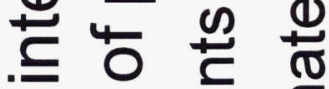

ᄃ त ह

. Ф ल

ญ ऽ 등

돈 원

ఏ) 늘 ఏ

근 느의 등

등 응 임 음

은 응 엉 몰

एญ
()

$\frac{1}{E}$

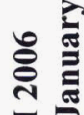

$\frac{\overline{0}}{\frac{10}{0}}$

으

$\underline{\sigma}$

$\frac{\sqrt{0}}{4}$

ल ख

E

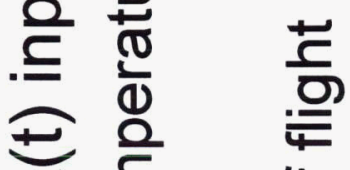

Е

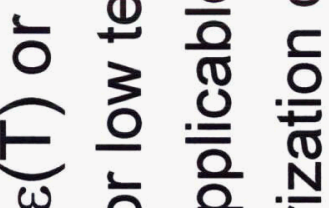

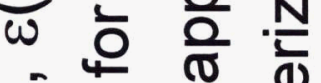

Е

○

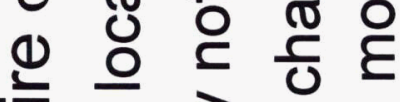

产 오 중

ปั

ฮ స

ल

ब1

을 중

ह

ర)

高

তัర ல

ป । । 